Original Research Paper

\title{
Automated Fall Armyworm (Spodoptera frugiperda, J.E. Smith) Pheromone Trap Based on Machine Learning
} \author{
${ }^{1}$ Monde M. Kabemba and ${ }^{2}$ Miyanda N. Moonga \\ ${ }^{1}$ Department of Computer Science, University of Zambia, Lusaka, Zambia \\ ${ }^{2}$ Department of Biological Sciences, University of Zambia, Lusaka, Zambia
}

${ }^{1}$ Simon H. Chiwamba, ${ }^{1}$ Jackson Phiri, ${ }^{2}$ Philip O.Y. Nkunika, ${ }^{1}$ Claytone Sikasote,

\author{
Article history \\ Received:17-09-2019 \\ Revised: 26-11-2019 \\ Accepted: 19-12-2019 \\ Corresponding Author: \\ Simon H. Chiwamba \\ Department of Computer \\ Science, University of Zambia, \\ Lusaka, Zambia \\ Email: shchiwamba@yahoo.com
}

\begin{abstract}
Maize is the main food crop that meets the nutritional needs of both humans and livestock in the sub-Saharan African region. Maize crop has in the recent past been threatened by the fall armyworm (Spodoptera frugiperda, J.E Smith) which has caused considerable maize yield losses in the region. Controlling this pest requires knowledge on the time, location and extent of infestation. In addition, the insect pest's abundance and environmental conditions should be predicted as early as possible for integrated pest management to be effective. Consequently, a fall armyworm pheromone trap was deployed as a monitoring tool in the present study. The trap inspection is currently carried out manually every week. The purpose of this paper is to bring automation to the trap. We modify the trap and integrate Internet of Things technologies which include a Raspberry Pi 3 Model B+ micro-computer, Atmel 8-bit AVR microcontroller, 3G cellular modem and various sensors powered with an off-grid solar photovoltaic system to capture real-time fall armyworm moth images, environmental conditions and provide real-time indications of the pest occurrences. The environmental conditions include Geographical Positioning System coordinates, temperature, humidity, wind speed and direction. The captured images together with environmental conditions are uploaded to the cloud server where the image is classified instantly using Google's pre-trained InceptionV3 Machine Learning model. Intended users view captured data including prediction accuracy via a web application. Once this smart technology is adopted, the labour-intensive task of monitoring will reduce while stakeholders shall be provided with a near real-time insight into the FAW situation in the field therefore enabling pro-activeness in their management of such a devastating pest.
\end{abstract}

Keywords: Internet of Things, Integrated Pest Management, Fall Armyworm, Raspberry Pi, Machine Learning

\section{Introduction}

The agriculture sector is a major contributor to job creation, health, family cohesion, wealth and political stability in most African economies (MoNDP, 2018). In the sub-Saharan Africa, maize is among the cash-crops and most grown crops in addition to being the staple food crop that meets the nutritional needs of both humans and livestock. It is grown in almost all parts of the country especially the rural areas (Smale et al., 2011). Therefore, the economical importance of maize and its role in securing Zambia's food and nutrition security including political stability cannot be over looked. Kwasek (2012) stated that food security is achieved when all people, at all times, have physical, social and economic access to sufficient, safe and nutritious food that meets their dietary needs and food preferences for an active and healthy life. Threats to food security include but not limited to climate change, droughts, emerging diseases, salty soils, fertilizer dependence and pests (Thompson, 2016). According to MoA (2019a), the greatest threats to national food and nutrition security in Zambia include illegal export of maize, also known as smuggling and fall armyworm infestation, among others. In this paper, we focus on the trapping of adult fall armyworm moths.

The main objective of this paper is to bring automation to the FAW trap and reduce on the labourintensive tasks which include field visits, manual 
counting and recording of the moths by field inspectors. We modify the trap and integrate Internet of Things (IoT). The IoT technologies include a Raspberry Pi 3 Model B+ micro-computer, Atmel 8-bit AVR microcontroller, $3 \mathrm{G}$ cellular modem and various sensors which include the pi camera, DHT11 temperature/humidity, Davis anemometer, powered with an off-grid solar photovoltaic system for capturing FAW images and environmental conditions in the field. This work is a build-up on the preliminary works that were published by Chiwamba et al. $(2019 ; 2018)$ and Chulu et al. (2019a; 2019b).

The system captures an image of the funnel path every second alongside environmental conditions and saves the image on local folder. The captured images together with environmental conditions are uploaded to the cloud server where the image is classified instantly using Google's pre-trained InceptionV3 machine learning model. The object is uploaded using the $3 \mathrm{G}$ cellular modem. Once the sending is successful, the image is deleted from the local drive on the Raspberry $\mathrm{Pi}$ as a way of managing the storage space dynamically and avoid over filling the SD card.

\section{Literature Review}

\section{Fall Armyworm}

The Fall Armyworm (FAW) (Spodoptera frugiperda) is a lepidopteran pest and it is native to the Americas (Day et al., 2017). The FAW is named after the Autumn (Fall) due to its presence during the said season in North America where it lays eggs and the larvae develops (Nagoshi et al., 2009; Plessis et al., 2018). According to Plessis et al. (2018), the FAW gained prominence when it was found to be attacking crops during the mid-19th Century in the Southern United States. Prasanna et al. (2018) further reports that the FAW has been found to be a more devastating pest than many others pest in Africa due to its ability to feed on over 80 different crop species; spread quickly across large geographic areas; and being persistent throughout the year. The FAW feeds on leaves and stems of a variety of plants including economically important maize, forage grass, rice, sorghum, sugarcane, cotton and vegetable crops, among others (Banson et al., 2019).

According to IAPRI (2019), the FAW mating occurs at high temperature and low humidity hence the high prevalence of the infestation in long periods of drought. The tropical habitat is ideal for the FAW to quickly reproduce and spread without pause. The FAW life cycle is a four staged one as shown in Fig. 1 and it takes about 30 days during the warm summer months and may extend to 60-90 days in cooler temperatures (IAPRI, 2019; 2018; Capinera, 2007).
It is believed that the FAW was introduced to Africa through transportation and subsequent widespread dispersal by the wind (Cock et al., 2017). In 2017/2018 season, the Zambia FAW infestation affected approximately 130,000 hectares of crops which resulted in over USD \$3 million for control costs during the early stages of its introduction (Otim et al., 2018). Day et al. (2017) reported that the impact of FAW ranges between $22 \%$ and $67 \%$ of yield in Ghana and Zambia, respectively. Similarly, Kenya and Ethiopia reported estimated yield losses of $32 \%$ and $47 \%$, respectively (Kumela et al., 2018). The above-mentioned losses will continue with the establishment of the FAW in Zambia.

Addressing the food security threat posed by FAW requires surveillance, monitoring and scouting of the spread of FAW to ensure adequate crop protection. Knowing the time, location and extent of infestation is vital to pest control. The current African response to FAW has faced several challenges arising from weak monitoring, surveillance and scouting systems. Other challenges include delayed recognition of the pest's widespread presence across the continent and lack of information about the dynamics of FAW migration that would allow effective prediction of where infestation might occur next. The spread of FAW has resulted in indiscriminate spraying of pesticides, often without knowing whether chemical control is necessary or effective within the local context (Prasanna et al., 2018).

Meagher (2001) stated that the monitoring of FAW male moths should be done with a multicomponent sex pheromone as a lure in traps. This is a type of insect trap that uses pheromones to lure insects to the trap. The trap can be used to detect early pest infestations such as the first occurrence of migratory pests; define areas of pest infestations; track the build-up of a pest population and help in decision making for pest management (Ahmad and Kamarudin, 2011; Baker et al., 2011; Anderson et al., 2012; Guerrero et al., 2014). Furthermore, Cluz et al. (2012) reported that the use of pheromone traps data in insecticide application was found to be more effective with a larval mortality rate above $90 \%$ in maize fields. Some notable pheromone traps are the sticky and Funnel (green lid/yellow funnel/transparent bucket) as shown in Fig. 2 and 3 respectively. Figure 4 shows the Funnel (green lid/yellow funnel/transparent bucket) components.

Historically, the sticky trap has been found to be more effective in capturing FAW male moths when positioned approximately one meter above the ground in and around the preferred hosts such a maize (Mitchell, 1979). The Funnel (green lid/yellow funnel/transparent bucket) pheromone trap has been found to outperform other pheromone traps including the sticky trap when trapping FAW moth in maize fields. Given its efficacy, it is no surprise that the Government of the Republic Zambia with the help of the FAO has secured over 2200 pheromone traps to be used in the monitoring and surveillance of the FAW moths (MoA, 2019b). 


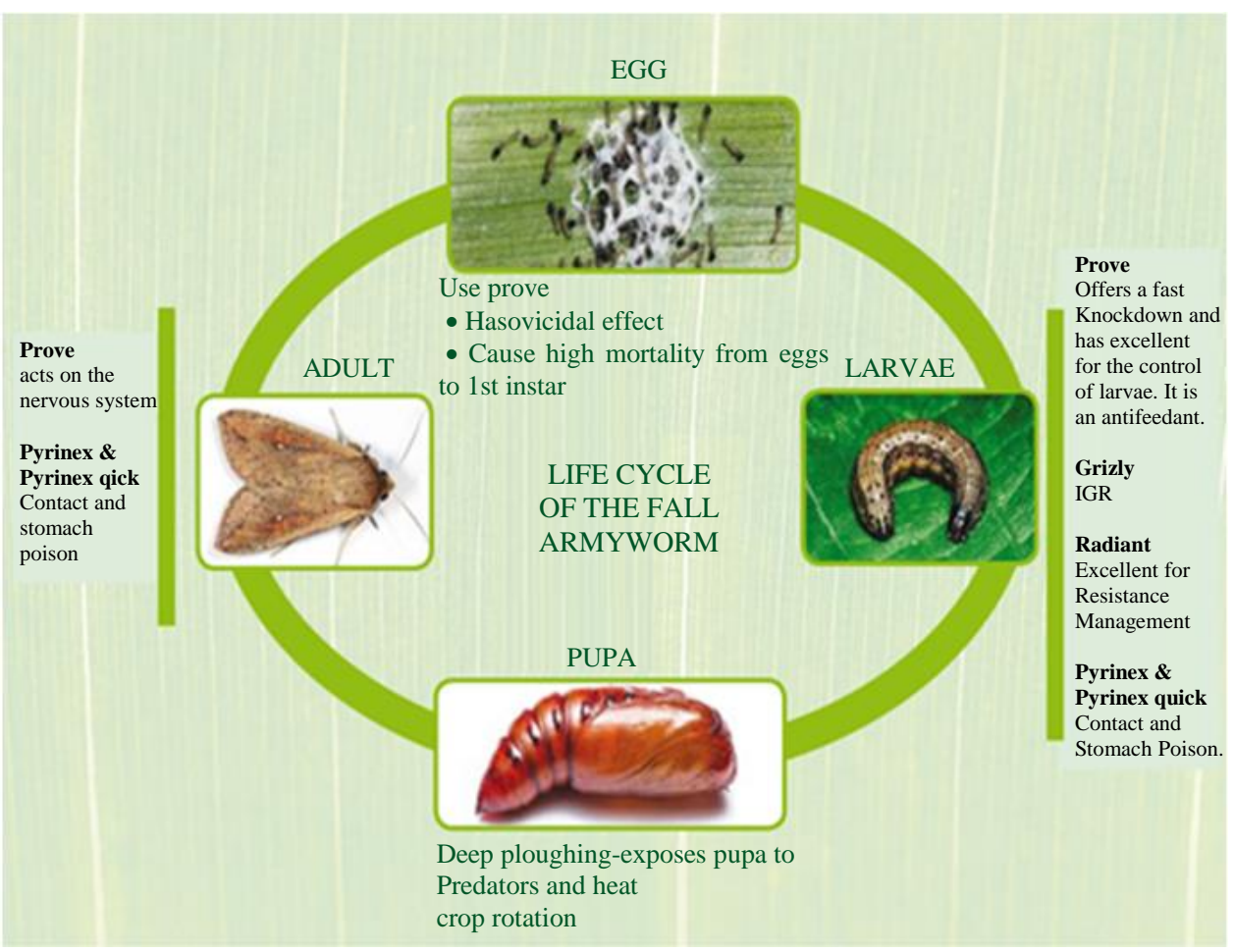

Fig. 1: FAW life cycle (Cereals, 2019)

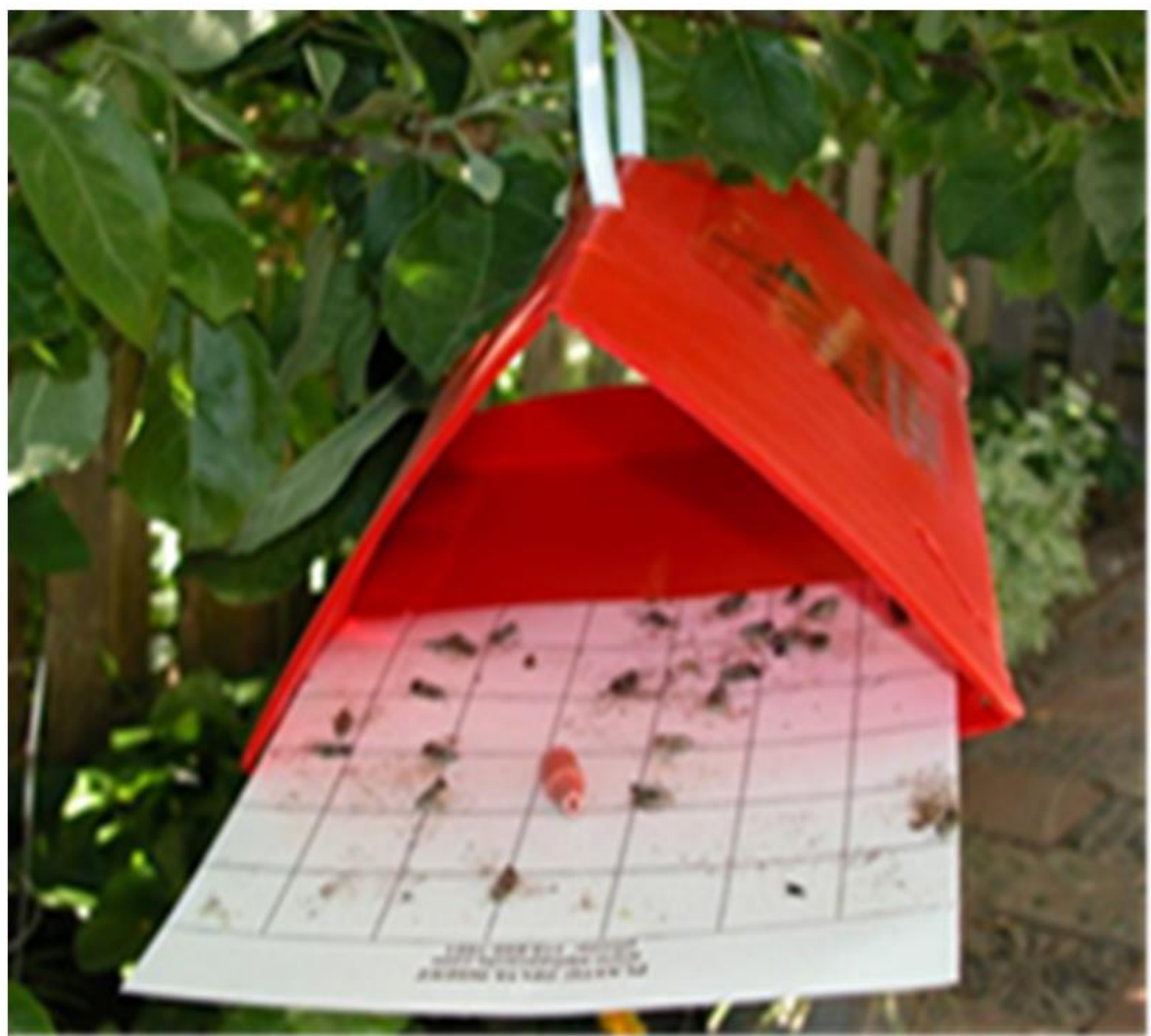

Fig. 2: Pheromone trap that employs a sticky surface (Indiamart, 2019) 


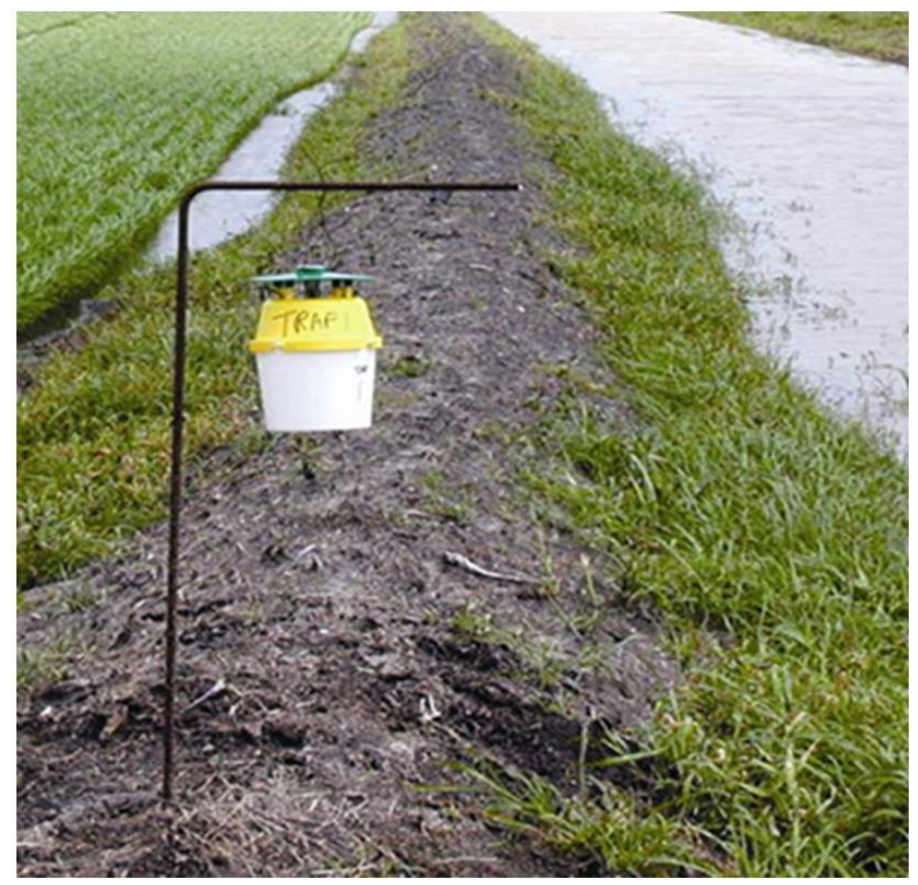

Fig. 3: Funnel/bucket pheromone trap (LSU, 2019)

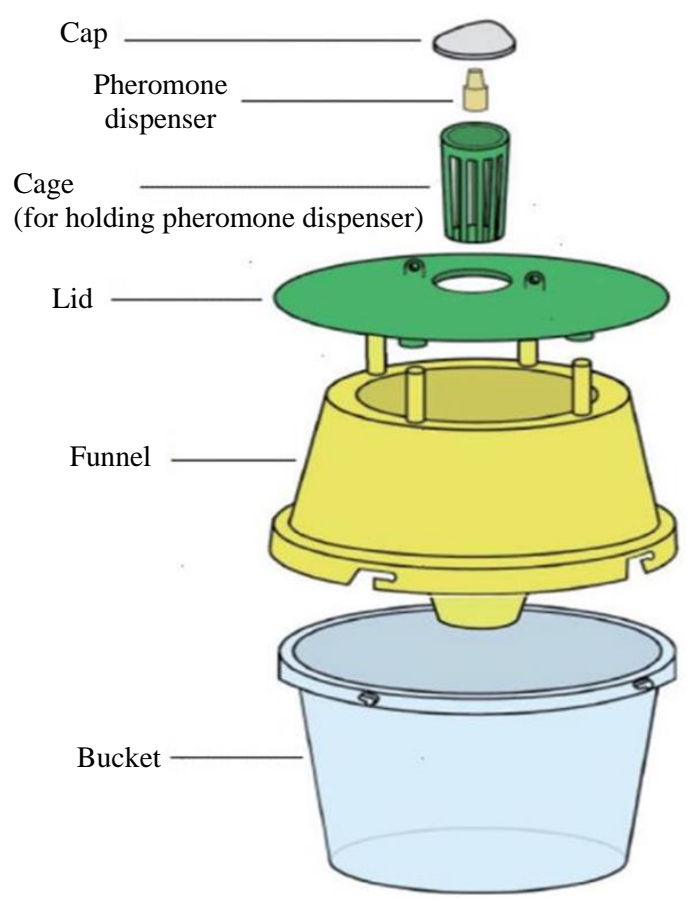

Fig. 4: Funnel/bucket pheromone trap components (FAO, 2018)

\section{Internet of Things}

In the recent years, the use of Information and Communication Technologies (ICT) and transducers to ensure optimum application of resources to achieve high crop yields and reduce operational costs in the agriculture sector has been observed. This concept of adding sensors and intelligence to basic objects is referred to as the Internet of Things (IoT). IoT refers to the billions of physical devices around the world that are now connected to the internet, collecting and sharing data using different types of protocols. IoT can be looked at as a network of objects which are embedded with technologies 
that helps to communicate and engage inside themselves and exterior environment (Chihana et al., 2018). The IoT concept was first developed in 1999 by a Radio Frequency Identification (RFID) development community (Shi et al., 2019; Bilal, 2017) and it has recently become more relevant to the practical world largely because of the growth of mobile devices, embedded and ubiquitous communication, cloud computing and data analytics.

\section{Application of IoT}

IoT has many applications including smart home, smart city, smart grids, smart retail, smart supply chain, industrial internet, connected car, connected health (digital health/telehealth/telemedicine) among others (Gour, 2018; Chihana et al., 2018). According to Muangprathub et al. (2019), the applications of IoT in the agriculture sector can be used to improve crop yields or quality and reduce costs. The seamless integration of transducers and the IoT in agriculture can raise the sector to levels which were previously unimaginable. IoT has the potential of streamlining procedures, reduce wastage and enhance productivity in the agriculture sector. According to Ayaz et al. (2019), IoT can help to improve the solutions of many traditional farming issues, like drought response, yield optimization, land suitability, irrigation and pest control by following the practices of smart agriculture. Further benefits can come from the quantity of fertilizer that has been utilized to the number of journeys the farm vehicles have made or the spray of pesticides (Ayaz et al., 2019). The major applications, services and transducers being used for smart agriculture applications are shown in Fig. 5.

\section{IoT Architecture}

IoT architecture consists of different layers of technologies supporting the scalability, modularity and configuration of IoT deployments in different scenarios. The IoT architecture has been presented using different layer numbers and names by many researchers (Yelizavet and Florentino, 2019; Chihana et al., 2018; Bilal, 2017; Sethi and Sarangi, 2017; Vermesan et al., 2013). In this paper, we discuss the ITU Y.2060 IoT architecture (Yelizavet and Florentino, 2019; Vermesan et al., 2013) shown in Fig. 6.

\section{IoT Application Layer}

The IoT application layer is the top most layer which covers "smart" environments/spaces in domains such as agriculture, homes, smart cities, grids, building, transport, retail, supply chain, healthcare environment and energy. It interacts directly with the end user by providing services and determining a set of protocols for message passing at the application level (Yassein et al., 2016). According to Haikun et al. (2018), connection to IoT management system platform by users is achieved using browser or client software through Ethernet/3G network.

\section{IoT Service and Application Support Layer}

In literature, some scholars refer to this layer as the Management Service Layer (Gour, 2018; Chihana et al., 2018). It is the layer that is responsible for processing the information through analytics, information extraction, security controls, process modeling and management of devices and gadgets. Business and process rule engines are among the most important features of the layer. IoT brings connection and interaction of objects and systems together providing information in the form of events or contextual data such as temperature of goods, current location and traffic data. Some of these events require filtering or routing to postprocessing systems such as capturing of periodic sensory data, while others require response to the immediate situations such as reacting to emergencies on patient's health conditions. The rule engines support the formulation of decision logics and trigger interactive and automated processes to enable a more responsive IOT system (Yelizavet and Florentino, 2019).

\section{IoT network Layer}

As the devices and gadgets produce enormous volumes of data, a robust and high performance wired or wireless network infrastructure is required to transmit this data. Due to the diversity of the IoT, it is often tied with heterogeneous protocols to support Machine-toMachine (M2M) networks and their applications. These networks can be in the form of a private, public or hybrid models and are built to support the communication requirements for latency, bandwidth or security (Haikun et al., 2018). According to Chihana et al. (2018), the network layer is responsible for ensuring that the transmission of transducer data to the next layer is achieved in a scalable and flexible manner.

\section{IoT Device Layer}

This is the layer that is made up of smart objects integrated with transducers that enable the interconnection of the physical and digital worlds allowing real-time information to be collected and processed (Bilal, 2017). According to Chihana et al. (2018), the layer consists of sensor networks, embedded systems, RFID tags and readers or other smooth sensors. The sensors have identification and capacity to take measurements such as temperature, air quality, wind speed, wind direction, humidity and pressure among others. The sensor may also have a degree of memory, enabling them to record a certain number of measurements. Most of these sensors require connectivity to the sensor gateways which can be through a Local Area Network (LAN) such as Ethernet and Wi-Fi connections or Personal Area Network (PAN) such as ZigBee, Bluetooth and Ultra Wideband (UWB) 
(Bilal, 2017). Some sensors do not require connectivity to sensor aggregators therefore their connectivity to backend servers/applications can be provided using Wide Area Network (WAN) such as GSM, GPRS and
LTE. For those sensors that use low power and low data rate connectivity, they typically form networks commonly known as Wireless Sensor Networks (WSNs) (Shi et al., 2019).

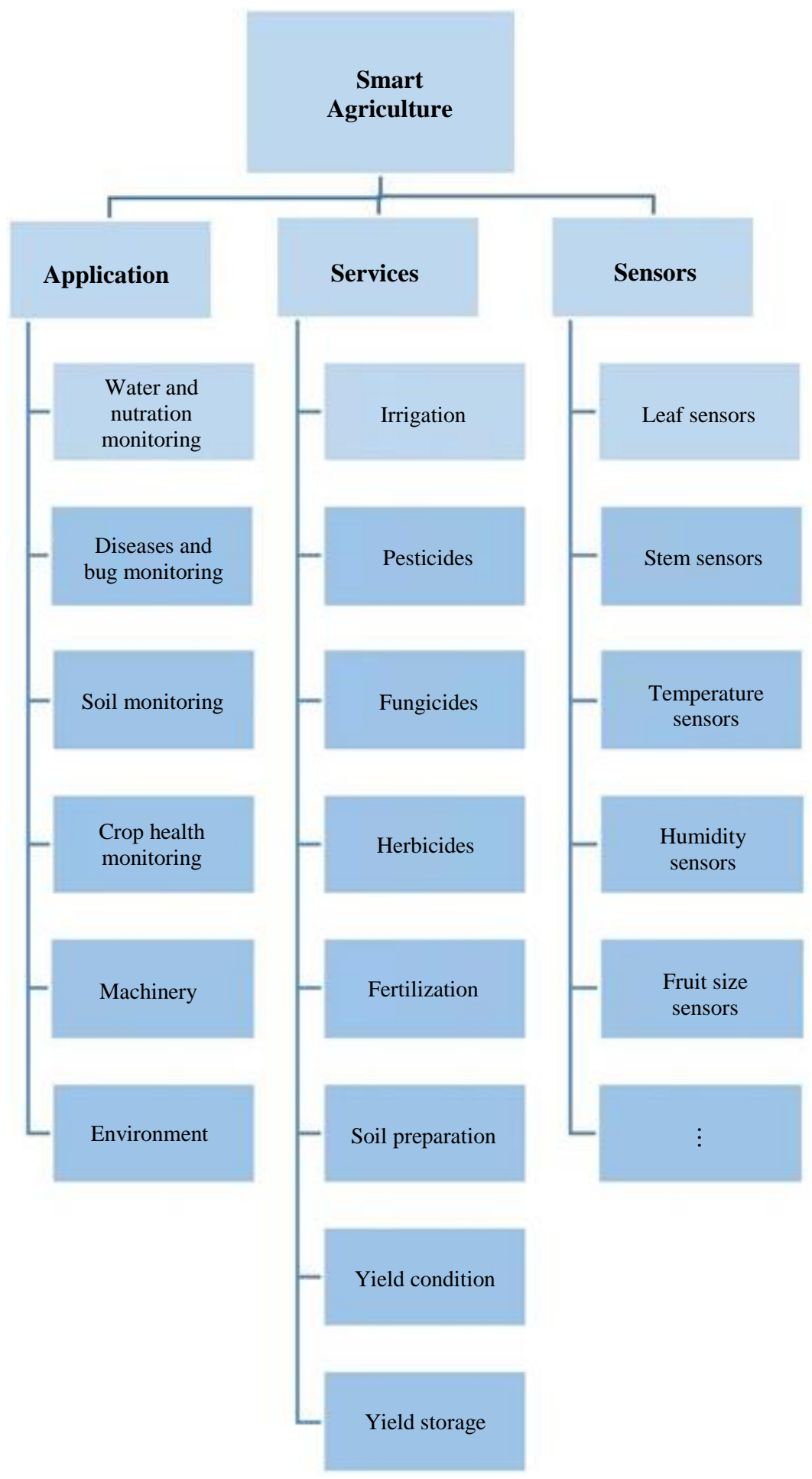

Fig. 5: Major applications, services and transducers for smart agriculture (Ayaz et al., 2019) 


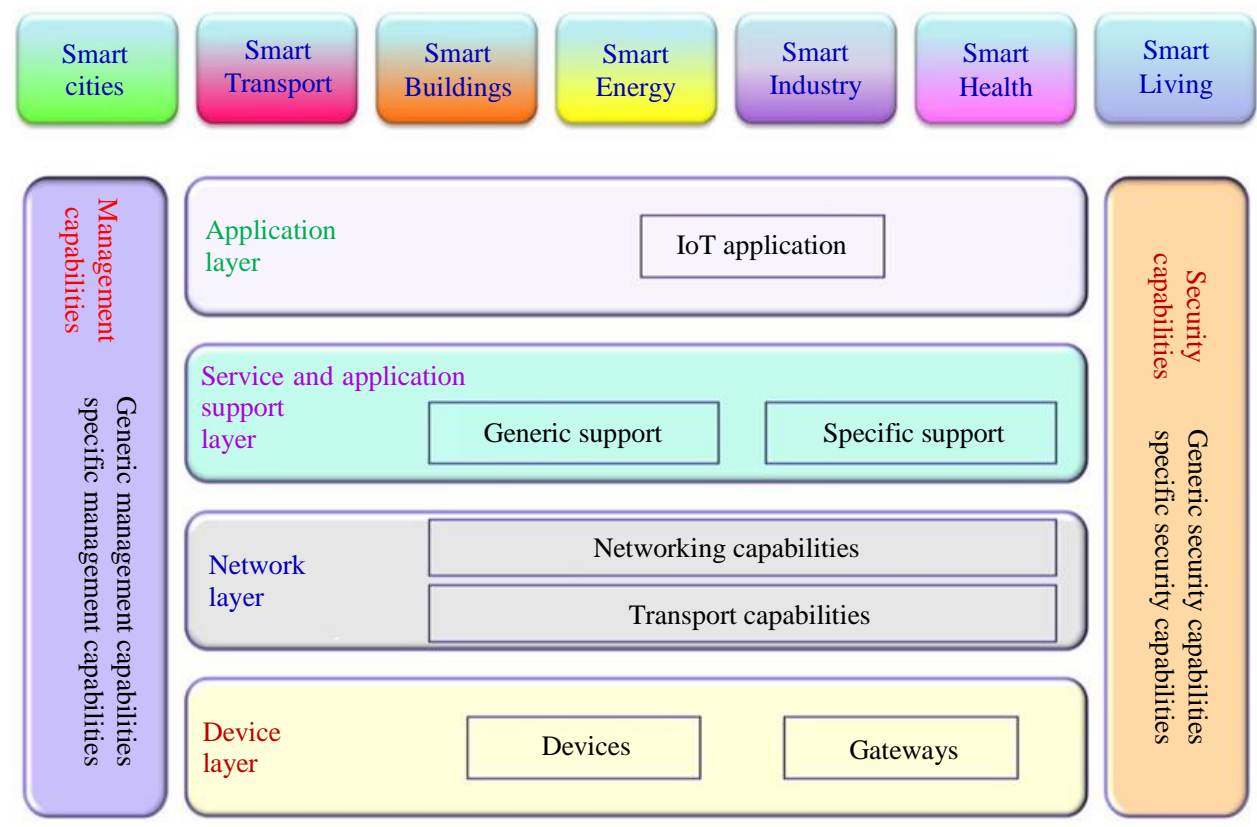

Fig. 6: IoT Architecture. (Vermesan et al., 2013)

\section{Machine Learning}

Machine Learning (ML) is a subfield of soft computing within computer science that studies the design of algorithms that can learn. Similarly, Patel (2019) define ML as the science of getting computers to learn and act like humans do and improve their learning over time in autonomous fashion by feeding them data and information in the form of observations and realworld interactions. ML includes adaptive mechanisms that empower computers to learn by example, learn by analogy and learn from experience (Negnevitsky, 2005).

ML algorithms include Convolutional Neural Network (CNN), Recurrent Neural Networks (RNNs), Long Short-Term Memory Networks (LSTMs), Stacked Auto-Encoders, Deep Boltzmann Machine (DBM) and Deep Belief Networks (DBN). According to Ding and Taylor (2016), the use of CNN for identifying and counting pest in field traps has the potential to effectively remove the human from the loop and achieve a complete automated, real-time pest monitoring system. Similarly, Martineau et al. (2017) reported that many researchers had acknowledged that CNN had outstanding performance in terms of image classification accuracy.

ML model can be built using transfer learning. Transfer learning allows building of accurate machine learning models in a timesaving way by starting from patterns that have been learned when solving a different problem (Marcelino, 2018). Instead of starting from scratch, it leverages on previous learning's and this is usually expressed through the use of pre-trained models. A pre-trained model is a model that was trained on a large benchmark dataset to solve a problem similar to the one that is being solved. In the work of Marcelino
(2018), it was reported that transfer learning had become the core of several state-of-the-art image classification solution. The pre-trained models include but not limited to Mask R-CNN, YOLOv2, MobileNet, VGG-Face Model, 3D Face Reconstruction from a Single Image, Google Inception, ImageNet, VGG-16, Xception, VGG19, ResNet50, InceptionV3 and InceptionResNetV2.

\section{Related Works}

In literature, some works use electronic devices to feed data into some control station. For example, the work of Marković et al. (2017) used a Raspberry Pi 3 microcomputer with four Cortex-A53 processing cores, $1.2 \mathrm{GHz}$ and two level of cache memory to monitor the Western Corn Rootworm (WCR) trapped by the sticky WCR pheromone trap. The pi camera was attached to the Raspberry Pi 3 and used to capture images of the sticky surface of pheromone trap. The counting of insects was done using the python module installed on the Raspberry Pi 3 by defining the number of pixels with dark or near dark colour and removing the impurities. While the system had a $0.3 \%$ accuracy, the system behaviour was not tested on unclear images and other objects that could be caught in the trap.

Eliopoulos et al. (2018) introduced a device for automatic detecting and reporting of crawling insects in urban environments which complied with the context of smart homes and smart cities. The device architecture embraced the IoT concepts by modifying the sticky pheromone trap and integrating it with a microcontroller, image sensor, infrared light sensor to detect targeted 
insect and capture they picture which were delivered to an authorized person/stakeholder using Wi-Fi. The results showed that the e-trap had potential application in tourism, hospitality, health, military and residential places. Furthermore, the trap achieved a detection accuracy ranging from 96 to $99 \%$.

In the work of Potamitis et al. (2014), an Arduino Mega2560 microcontroller platform (Atmel ATmega2560 microcontroller, $16 \mathrm{MHz}$ clock speed, 256 KB Flash, 8 KB SRAM, 4 KB EEPROM) powered by a 4.8 Volt battery NiMH power supply was used to perform the counting of insects entering the trap and recognize the species. In order to sense the insects, an optoelectronic (TCRT5000) sensor and phototransistors were placed at the entrance of the McPhail trap to detect light interruption due to the partial occlusion from insect's wings as they flew into the trap. The output of the optoelectronic sensor was analog and, it was sent to the Arduino Mega2560 microcontroller to perform the counting of insects passing the beam and recognize the class the insects belonged to. The events was stored in the device's memory and transmitted once per day as text message via the GSM expansion board SM5100B to a predefined recipient. With the real time count and classification of insects present per trap, stakeholder's efficiency was enhanced by knowing the time and location of insect infestations as early as possible.

Similarly, Facello and Cavallo, 2013), used an Arduino Uno microcontroller platform (Atmel ATmega328P microcontroller, $16 \mathrm{MHz}$ clock speed, 2KB Flash, 2 KB SRAM, 1 KB EEPROM) powered by a $43 \mathrm{~W}$ solar panel, 18Ah $\mathrm{Pb}$ battery to monitor pests in vineyards and orchards. The trap was equipped with a $2592 \times 1944$ pixels (5Mpixels) wide-angle lens $6 \mathrm{~mm}$ focal length IP camera, temperature/humidity sensor and LED illuminator. The sensor, led and camera were connected to the Arduino Uno board running a custom firmware developed for the application. The led and IP camera were powered separately using a $12 \mathrm{~V}$ and up to $0.3 \mathrm{~A}$ power supply because the $5 \mathrm{~V}$ and $0.04 \mathrm{~A}$ from Arduino was not sufficient. The Arduino Uno communicated and was controlled through a standard USB connection on the embedded miniITX pc-board (Intel DN2700MT). The main software running on the mini-ITX pc-board governed all the necessary operations needed to acquire, store and transmit the images and environmental information. The images were stored on the a local disk and they were automatically uploaded and synchronized with a free file hosting service on the web using a standard Wi-Fi connection. Remote users were given access to the images by simply connecting to the webpage.

Zhong et al. (2018) designed and implemented a visionbased counting and classification system for flying insects using a YOLO pre-trained model and Support Vector Machines learning algorithm. The system was based on a sticky pheromone trap that was installed in the field to trap flying insects and camera attached to a raspberry pi to capture real-time images. When compared with the conventional methods, the test results showed an average counting accuracy of $92.50 \%$ and average classifying accuracy of $90.18 \%$. These results were breakthrough towards smart and intelligent agriculture applications which could forecast the occurrence probability of pests to enable agricultural workers provide suitable prevention and control measures.

We see more work in Muminov et al. (2017) when a solar powered audible intelligent bird repeller system is developed based on Arduino UNO microcontroller to deter domestic birds which are a major threat in the field of agriculture causing damage to economic field crops, storage houses and also dirtying human life area. The other system components included a solar panel $(7 \mathrm{~W}$, $12 \mathrm{~V}$ ), an intelligent PWM solar charge controller, 12V battery, MP3 Player, amplifier (Stereo 20W Class D Audio Amplifier - MAX9744), two 20W speakers, three sonar sensor and PIR sensor. The SD Card was loaded with domestic bird's predators' calls and special sounds (such as gunshot sounds) stored using the MP3 file format. The signal level of predators' calls and special sounds were played out via the speakers and increased using the amplifier while the solar panel was used to charge the battery and power the amplifier, speaker and Arduino Uno. The other components were powered by the Arduino Uno. The system algorithm was designed in such a way that it was able to play special sounds which had not played for a long time. This technique was applied due to an acknowledgment that birds can learn sounds overtime and that would render the repeller ineffective.

Other works proposed a solar powered rice black bug light trap that would help reduce rice black bug infestation based on an Arduino Uno microcontroller platform and $\mathrm{C}++$ programming language (Calderon, 2017). The notable components included a $12 \mathrm{~V} 20 \mathrm{~W}$ standard polycrystalline solar cells panel, $30 \times 40 \times 15$ (width $\times$ length $\times$ thickness) clear acrylic square box, 150 LED size $7 \times 7 \mathrm{~mm}$, 5A battery charger, $12 \mathrm{~V} 14 \mathrm{Ah}$ Sealed Lead Acid battery, light sensor switch circuit, DS1307 Real-Time Clock (RTC) and high voltage circuit of mosquito trap all enclosed in steel box to prevent any damages. The proposed design was assessed in terms of efficiency, functionality, maintainability, reliability, usability and cost-effectiveness of the materials using questionnaires and a 3.7 overall weighted mean was observed where experts' response was highly acceptable.

A custom-made microprocessor hardware embedded with a SIM card and the Global System for Mobile Communications (GSM) antenna to transmit accumulated detection results of all insects entering the 
trap using Short Message Service (SMS) to the base station is seen in the work of Potamitis et al. (2015). The insects were lured and as they flew into the trap, an optoelectronic sensor composed of an array of photoreceptors that acted as a receiver and an array of infrared LEDs on the opposite side of the circular entrance guarded the entrance by forming a light gate. The insect wings interrupted the flow of infrared light from emitter to receiver. The optoelectronic sensors captured an analog signal of the wingbeat recording which was sent to the microprocessor embedded in the trap. The job of the microprocessor was to analyze the frequency content of the acquired recording and calculate the distance metric from the spectrum of the unknown incoming recording to the spectrum of pre-stored prototype spectra of the pest results in order to identify the insect. Other efforts are seen the in the work of Holguin et al. (2010), when two electronic trap prototypes based on a microcontroller from Microchip Technology Inc. Model PIC18F8722A to automate the labour-intensive operations of monitoring insect populations and reduced the cost of integrated pest management programmes are compared. The trap in question was the bucket pheromone. The first trap used Light Dependent Resistor (LDR) sensors and the second one used Infrared (IR) sensors. The LDR-based traps were tested in a laboratory environment while the IR-based traps were tested in apple fields.

\section{Materials and Methods}

The modification of the FAW pheromone trap to bring about automation started with the PV systems design followed by trap fabrication and ended with integration. The high-level systems design of the automated FAW pheromone trap is shown in Fig. 7 and the Modified FAW Trap Block Diagram is shown in Fig. 8.

\section{Step I- Solar PV Systems Design}

The researchers growing energy needs can be satisfied by the enormous energy from the sun which provides over 150,000 terawatts of power to the Earth (Crabtree and Lewis, 2007; Camacho et al., 2010). Crabtree and Lewis (2007) reported that the Earth surface only receives about half of that energy while the other half is reflected to the outer space. The main components of a solar PV system include solar panel, charge controller and battery. Figure 9 and this section highlights the procedures used to determine the ratings and quantities for each of these components.

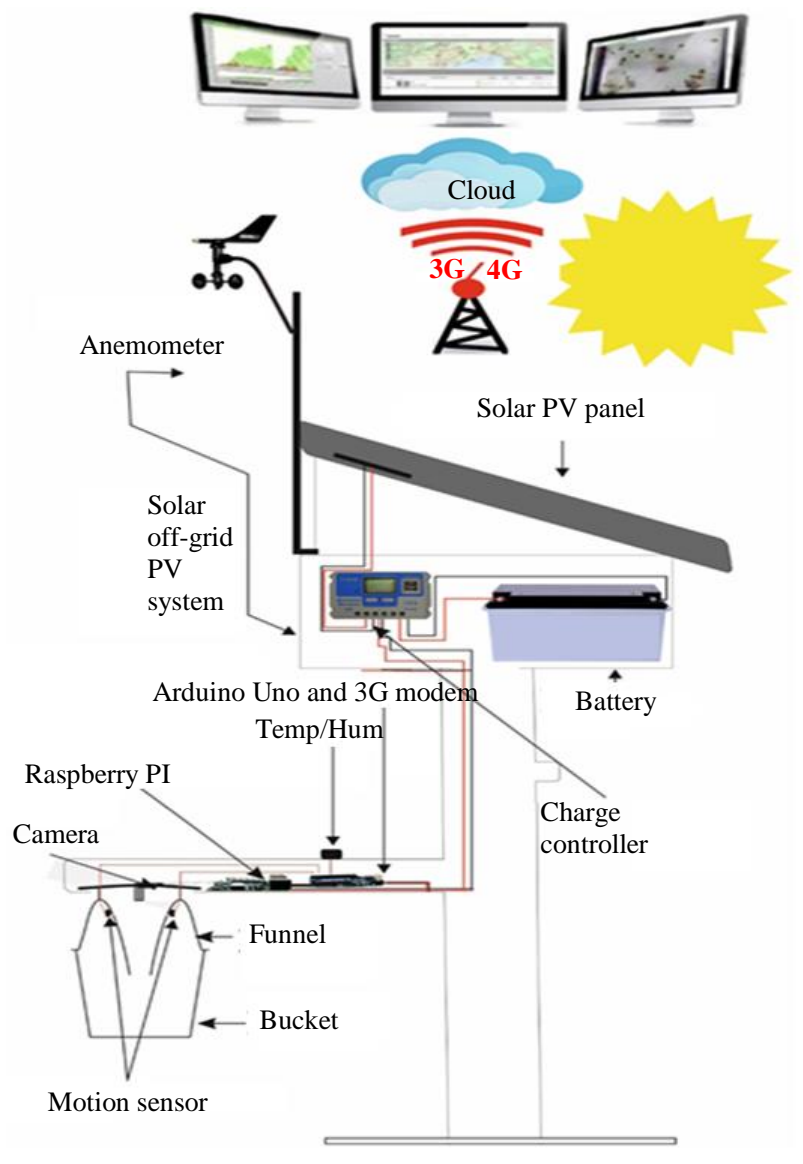

Fig. 7: High level design of the automated FAW pheromone trap 


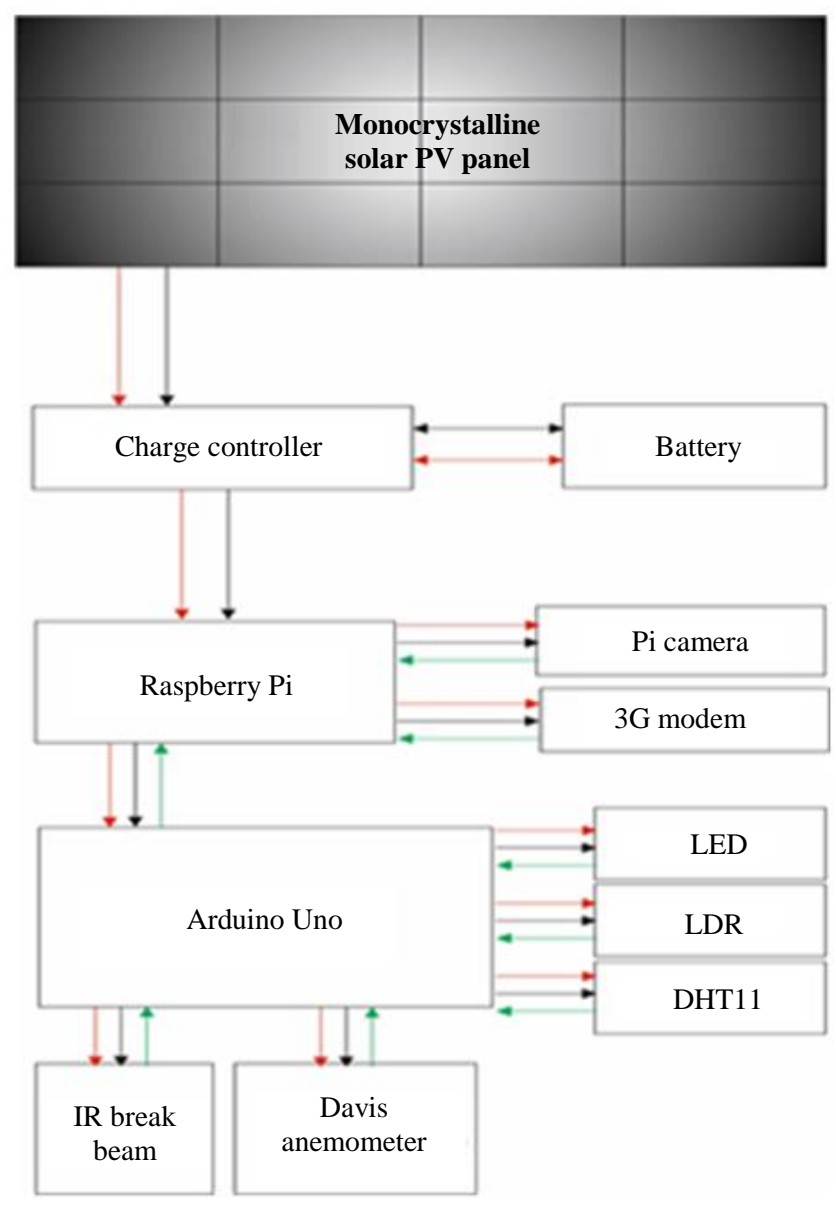

Fig. 8: Modified FAW trap block diagram

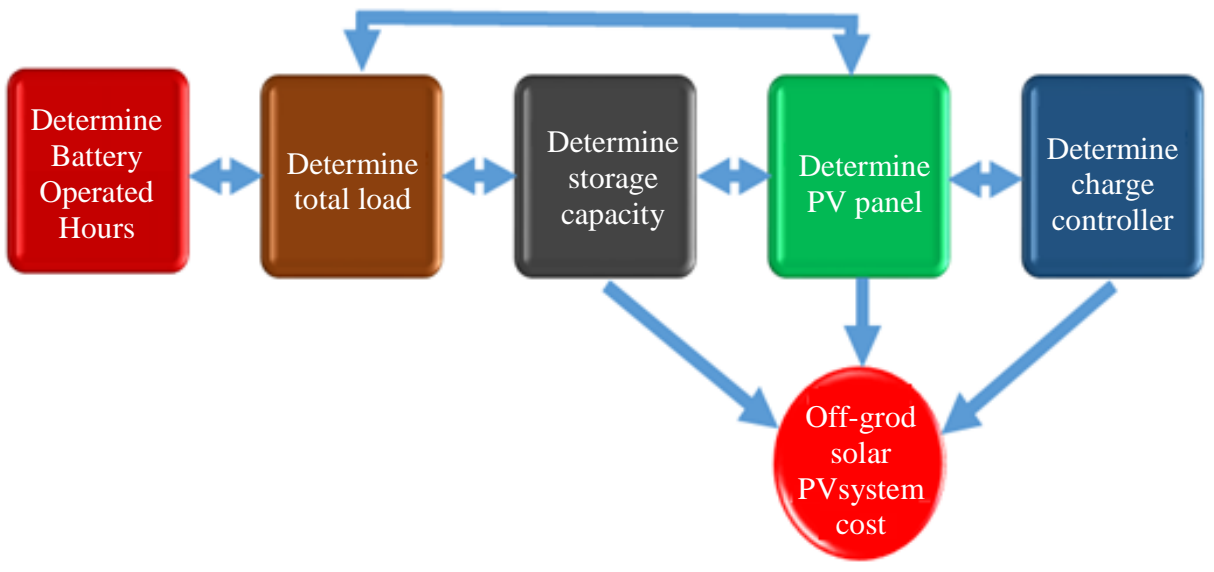

Fig. 9: Solar PV Design Model

\section{Determine Battery Operated Hours}

Climatemps (2019) reported that Lusaka, the capital city of Zambia at latitude $15^{\circ} 25^{\prime} \mathrm{S}$ and longitude $28^{\circ} 27^{\prime} \mathrm{E}$ receives a minimum of $5 \mathrm{~h}$, an average of 7:35 $\mathrm{h}$ and a maximum of 09:42 $\mathrm{h}$ sunshine per day. This is in agreement with the results obtained by (Mwanza et al., 2017). We determined the battery operated hours using Equation 1:

$T b=T d-T s$

Where:

$T b=$ The battery operated hours (hrs) 
$T d=$ The total hours in day (hrs)

$T s=$ The minimum sunshine hours per day (hrs)

\section{Determine Total Load}

Many researchers modify the already existing traps by integrating single-board computers, microcontrollers and various sensors (Holguin et al., 2010; Facello and Cavallo, 2013). At this stage, we identified all the electronic components to be used to realize an automated energy independent pheromone trap and used Equation 2 to estimate the load for the Off-grid solar PV system:

$$
p=\sum_{k=1} i_{k} \times v_{k} \times t_{k}
$$

Where:

$P=$ The total load (Wh)

$i_{k}=$ The current for a single component (A)

$v_{k}=$ The voltage for a single component $(\mathrm{V})$

$t_{k}=$ the running hours for single component (hrs)

The subsections that follow gives detailed descriptions and specifications of the components used.

\section{Single-Board Computer and Microcontroller}

A Single-Board Computer (SBC) is a complete computer built on a single circuit board, with microprocessor(s), memory, Input/Output (I/O) and other features required of a functional computer. Some notable SBC's available on the market include Raspberry Pi, The Beagles PandaBoard, MK802, MK808, Cubieboard, MarsBoard, Hackberry Udoo and MinnowBoard among others (Maksimović et al., 2016). In the work of Maksimović et al. (2016), the Udoo is found to be the best in performance but expensive while Raspberry Pi remained an inexpensive computer and very successful in diverse range of research applications in Internet of Things (IoT). In addition, the Raspberry Pi offers support for a large number of input/output peripherals, network communication and can interface with many different devices and used in a wide range of applications. Table 1 gives the Raspberry Pi 3 Model $\mathrm{B}+$ specifications.

A microcontroller is a small computer on a single integrated circuit and Arduino Uno is among the mostly used (Maksimović et al., 2016; Ferdoush and Li, 2014). Arduino is an open-source single-board microcontroller development platform with flexible, easy-to-use hardware, software components and supports two working modes: stand-alone or slave connected to a computer via USB cable (Cvijikj and Michahelles, 2011). Table 2 gives the Arduino Uno Rev 3 specifications.

\section{DHT11 Temperature/Humidity Sensor}

The DHT11 is digital environment sensor used to measure the moisture and temperature of the surrounding air. It is low cost temperature and humidity sensor. Characteristics of this sensor are given in Table 3. The sampling rate for the DHT11 is $1 \mathrm{~Hz}$ or one reading every second, the operating voltage for sensor ranges from 3 to 5 volts, while the max current used when measuring is $2.5 \mathrm{~mA}$. In the work of Ferdoush and $\mathrm{Li}$ (2014), the DHT11 is used to measure the humidity and temperature in grape fields. Table 3 gives the DHT11 sensor specifications.

\section{IR Break Beam}

The use of light sensors in detecting and counting of insects has been seen in the of works Potamitis et al. (2015; 2014) and Holguin et al. (2010). One of the notable light sensor is the Infrared (IR) break-beam. According to Adfruit (2019), the Infrared (IR) breakbeam is a motion detector with an emitter side that sends out a beam of human invisible IR light and a receiver across the way which is sensitive to that same light. Adfruit (2019) goes on to state that the break beams are faster and allow better control of where you want to detect the motion as compared to Passive IR sensing. The IR break beam is offered as $3 \mathrm{~mm}$ or $5 \mathrm{~mm}$. The $3 \mathrm{~mm}$ sensing distance is about $25 \mathrm{~cm}$ while the $5 \mathrm{~mm}$ is about $40 \mathrm{~cm}$. Both can be powered from $3.3 \mathrm{~V}$ or $5 \mathrm{~V}$. The $5 \mathrm{~V}$ power gives a better range and it is the recommend one. Table 4 gives the $3 \mathrm{~mm}$ sensor specifications.

\section{Pi Camera Module}

The raspberry pi camera module $\mathrm{v} 2$ is a high definition vision sensor that comes with a Sony IMX219 sensor (Raspberry, 2019). The IMX219 is a diagonal $4.60 \mathrm{~mm}$ (Type 1/4.0) Complementary Metal-Oxide-Semiconductor (CMOS) active pixel type image sensor with a square pixel array and $8.08 \mathrm{M}$ effective pixels. It operates with three power supplies, analogue $2.8 \mathrm{~V}$, digital $1.2 \mathrm{~V}$ and IF $1.8 \mathrm{~V}$ and has low power consumption drawing between 200-250 mA. It achieves high sensitivity, low dark current and no smear through the adoption of R, G and B primary colour pigment mosaic filters. This chip features an electronic shutter with variable charge-storage time. The camera module can be used to take high-definition video at 1080p30, 720p60 and VGA90 video modes, as well as stills photographs. According to Raspberry (2019), it is attached to Raspberry Pi through the Camera Serial Interface (CSI) port and it works with Raspberry Pi 1, 2, 3 and 4 models. It can be accessed through the Multimedia Abstraction Layer (MMAL) and Video4Linux (V4L) Application Program Interfaces (APIs) in addition to numerous third-party libraries built for it such as Picamera Python. In the works of Marković et al. (2017), the pi camera is attached to the Raspberry Pi 3 and used to capture images of the sticky surface of WCR pheromone. Table 5 gives the pi camera module V2 specifications. 
Table 1: Raspberry Pi 3 Model B+ specifications

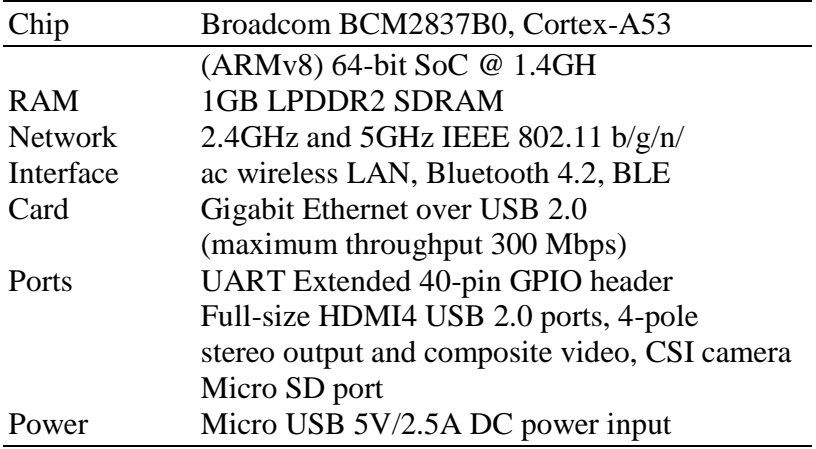

Table 2: Arduino Uno Rev 3 specification

\begin{tabular}{ll}
\hline Microcontroller & ATMega328P \\
\hline Operating Voltage & $5 \mathrm{~V}$ \\
Input Voltage (recommended) & $7-12 \mathrm{~V}$ \\
Input Voltage (limit) & $6-20 \mathrm{~V}$ \\
Digital I/O Pins & 14 (of which \\
& provide PWM output) \\
PWM Digital I/O Pins & 6 \\
Analog Input Pins & 6 \\
DC Current per I/O Pin & $20 \mathrm{~mA}$ \\
DC Current for 3.3V Pin & $50 \mathrm{~mA}$ \\
Flash Memory & $32 \mathrm{~KB}$ (ATmega328P) \\
& of which 0.5 KB used \\
SRAM & by bootloader \\
EEPROM & $2 \mathrm{~KB}$ (ATmega328P) \\
Clock Speed & $1 \mathrm{~KB}$ (ATmega328P) \\
LED_BUILTIN & $16 \mathrm{MHz}$ \\
Length & 13 \\
Width & $68.6 \mathrm{~mm}$ \\
Weight & $53.4 \mathrm{~mm}$ \\
\hline
\end{tabular}

Table 3: DHT11 sensor specifications

\begin{tabular}{ll}
\hline & DHT11 \\
\hline Temperature Range/Accuracy & 0 to $50 / \pm 2 \mathrm{C}$ \\
Humidity Range/Accuracy & $20-80 \% / \pm 5 \%$ \\
Sampling Rate & $1 \mathrm{~Hz}$ (one reading every second) \\
Size & $15.5 \times 12 \times 5.5 \mathrm{~mm}$ \\
Operating Voltage & 3 to $5 \mathrm{~V}$ \\
Max Current During & $2.5 \mathrm{~mA}$ \\
Measuring & \\
\hline
\end{tabular}

Table 4: IR Break beam $3 \mathrm{~mm}$ sensor specifications

\begin{tabular}{ll}
\hline Sensing Distance & Approx. 25cm/10" \\
\hline Power Voltage & 3.3 to 5.5VDC \\
Emitter Current Draw & $10 \mathrm{~mA} @ 3.3 \mathrm{~V}, 30 \mathrm{~mA} @ 5 \mathrm{~V}$ \\
Output Current & $100 \mathrm{~mA}$ sink \\
Capability of receiver: & $10^{\circ}$ \\
Transmitter/Receiver & \\
LED Angle: $10^{\circ}$ & \\
Cable Length & $234 \mathrm{~mm} / 9.2$ \\
Dimensions: & $20 \times 1 \times 8 \mathrm{~mm} / 0.8^{\prime \prime} \times 0.4 \times 0.3^{\prime \prime}$ \\
Weight (of each half) & $3 \mathrm{~g}$ \\
Response Time: & $<2 \mathrm{~ms}$ \\
\hline
\end{tabular}

Table 5: Pi camera Module V2 specifications

\begin{tabular}{ll}
\hline Size & $25 \times 23 \times 9 \mathrm{~mm}$ \\
\hline Weight & $3 \mathrm{~g}$ \\
Power Voltage & 3.3 to 5.5VDC \\
Still Resolution & 8 Megapixels \\
Video mode & $1080 \mathrm{p} 30,720 \mathrm{p} 60$ and $640 \times 480 \mathrm{p} 60 / 90$ \\
Sensor & Sony IMX219 \\
Sensor resolution & $3280 \times 2464$ pixels \\
Sensor image area & $3.68 \times 2.76 \mathrm{~mm}(4.6 \mathrm{~mm}$ diagonal $)$ \\
Pixel size & $1.12 \times 1.12 \mu \mathrm{m}$ \\
Optical size & $1 / 4 "$ \\
\hline
\end{tabular}

Table 6: Quectel EC25 Mini PCle 4G/LTE module specifications

\begin{tabular}{ll}
\hline Shield & Raspberry Pi 3G-4G/LTE Base Shield V2 \\
\hline LTE FDD & B1/B3/B5/B7/B8./B20 \\
LTE TDD & B38/B40/B41 \\
WCDMA & B38/B40/B41 \\
GSM & B3/B8 \\
Data & LTE FDD: Max 150Mbps (DL)/Max \\
Speeds & 50 Mbps (UL); LTE TDD: Max 130 Mbps \\
& (DL)/Max 35 Mbps (UL); DC-HSDPA: \\
& Max 42 Mbps (DL); HSUPA: Max \\
& 5.76 Mbps (UL); WCDMA: Max 384Kbps \\
& (DL)/Max 384Kbps (UL); EDGE: Max \\
& 296 Kbps (DL)/Max 236.8 Kbps (UL); GPRS: \\
& Max 107 Kbps (DL)/Max 856 Kbps (UL) \\
Interface & USB 2.0 with High Speed up to 480 Mbps; \\
& 1.8V/3.0V (U)SIM Card; UART×1 \\
Protocol & TCP/UDP/PPP/FTP/HTTP/NTP/PING \\
& QMI/CMUX/HTTPS/SMTP/MMS/ \\
STPS/SMTPS/SSL/FILE \\
OS & Windows XP - 10, Windows CE 5.0-7.0* \\
Current & ; Linux 2.6-4.1; Android 4.x-7.x \\
Consum- & 750 mA @ @ WCDMA data transfer, Typ. \\
ption & (GNSS OFF); 950 mA @LTE data transfer, \\
& Typ. (GNSS OFF); 75Ma@ Searching, GNSS, \\
& Typ. 55 mA @ Tracking, GNSS, Typ \\
Output & Class 3 (23 dBm \pm 2 dB) for LTE; Class 3 E2 \\
Power & (24 dBm +1/-3 dB) for UMTS; Class (27 dBm \\
& $\pm 3 \mathrm{~dB})$ for EDGE; 850/900 MHz; Class E2 \\
& (26 dBm \pm 3 dB) for EDGE 1800/1900 MHz; \\
& Class 4 (33 dBm \pm 2 dB) for GSM 850/900 MHz \\
& Class 1 (30 dBm \pm 2 dB) for GSM;1800/1900 MHz \\
&
\end{tabular}

\section{Quectel EC25 Mini PCIe 4G/LTE Module}

This is an interface between the raspberry pi and internet. According to Sixfab (2019a), the Quectel EC25 Mini PCIe is a series of LTE category 4 module adopting standard PCI Express ${ }^{\circledR}$ MiniCard form factor (Mini PCIe). Sixfab (2019a) goes on to state that it is optimized specially for Machine-to-Machine (M2M) and IoT applications and delivers $150 \mathrm{Mbps}$ downlink and $50 \mathrm{Mbps}$ uplink data rates. The EC25 is integrated with Global Navigation Satellite System (GNSS) to provide quicker, accurate and dependable positioning. It is inserted in the Raspberry Pi 3G-4G/LTE base shield V2 which has both the UART and USB communication for the raspberry (Sixfab, 2019b). For detailed specifications Table 6 . 
Table 7: Davis Anemometer specifications

\begin{tabular}{ll}
\hline Range: Wind Speed & 1 to $200 \mathrm{mph}, 1$ to $173 \mathrm{knots}$, \\
\hline & 0.5 to $89 \mathrm{~m} / \mathrm{s}, 1$ to $322 \mathrm{~km} / \mathrm{h}$ \\
Range: Wind Direction & $0^{\circ}$ to $360^{\circ}$ or 16 compass points \\
Range: Wind Run & 0 to 1999.9 miles $(1999.9 \mathrm{~km})$ \\
& $\pm 2 \mathrm{mph}(2 \mathrm{kts}, 3 \mathrm{~km} / \mathrm{h}, 1 \mathrm{~m} / \mathrm{s})$ \\
Accuracy: Wind Speed & or $\pm 5 \%$, whichever is greater \\
& $\pm 7^{\circ}$ \\
Accuracy: Wind Direction & $\pm 5 \%$ \\
Accuracy: Wind Run & $1 \mathrm{mph}(1 \mathrm{knot}, 0.1 \mathrm{~m} / \mathrm{s}, 1 \mathrm{~km} / \mathrm{hr})$ \\
Resolution: Wind Speed & $1^{\circ}\left(0^{\circ}\right.$ to $\left.355^{\circ}\right), 22.5^{\circ}$ between \\
Resolution: Wind Direction & compass points \\
Resolution: Wind Run & $0.1 \mathrm{~m}(0.1 \mathrm{~km})$ \\
Measurement Timing: Wind & $2.252 \mathrm{nds}$ \\
Speed Sample Period & \\
\hline
\end{tabular}

\section{Davis Anemometer}

The anemometer and wind vane are the other devices used for sensing environmental conditions. The anemometer measures the wind speed while the wind vane measures wind direction. Davis (2019) has combined the two functions and called the devices Davis anemometer. Cactus (2014) has shown that the Davis anemometer can be interfaced with Arduino Uno to create a weather station, this is in agreement with the results obtained by Kong (2017). Table 7 lists some of the Davis anemometer specifications.

\section{Determine Storage (battery) Capacity}

As PV cells generate electricity during sunshine, a rechargeable battery system is required to store it for use in the absence of sunshine. Currently, the battery types include Lithium-ion, Nickel, Sodium sulfur, Flow redox and Lead acid among other. According to Daniel et al. (2014) lead acid batteries have been found to be reliable and cost-effective while Maya et al. (2018) reports that the lithium-ion is a high energy efficiency battery rated at $90 \%$ despite the high cost and safety concerns compared to the lead acid at $85 \%$. To determine the battery size, we used Equation 3:

$$
A h=\frac{E}{V d c} \times F_{\text {Safe }}
$$

Where:

$A h=$ The battery Amp hour (Ah)

$E \quad=$ The total load (Wh)

$V d c=$ The system Voltage preferred $(\mathrm{V})$

$F_{\text {safe }}=$ The Safe Factor

\section{Determine the Solar PV Panel}

Conversion of the solar energy to electricity can either be direct or indirect. According to Taşçığlu et al. (2016), the indirect method is through collecting and Concentrating the Solar Power (CSP) to produce steam which is then used to drive a turbine to provide the electricity while Bayrak and Cebec (2011) states that the direct method uses the Photovoltaic (PV) cells. The most used PV cells are the polycrystalline and monocrystalline. Abdelkader et al. (2010) reported that the monocrystalline PV cells were more efficient compared to the polycrystalline and this is in agreement with results obtained by several authors (Taşçıŏglu et al., 2016; Husain et al., 2018) a. We used Equation 4 to determine the solar PV panel wattage size (AlShemmary et al., 2019):

$$
P V W=\frac{F}{T} \times F_{\text {Safe }}
$$

Where:

$P V W=$ The $\mathrm{PV}$ power required $(\mathrm{W})$

$E \quad=$ The total load (Wh)

$T=$ The minimum sunshine hours per day (hrs)

$F_{\text {safe }}=$ The Safe Factor

\section{Determine the Charge Controller Capacity}

Storing power from solar PV cells into a battery requires a charge controller. According to Maya et al. (2018), charge controller controls the rate of flow of the charge carriers and protect the battery from overcharging in addition to preventing battery over discharge and electrical overload. We determined the charge controller capacity by applying Equation 5:

$C C A O=\frac{P V W}{V d c} \times F_{\text {Safe }}$

Where:

$C C A O=$ The charge controller amp out (A)

$P V W=$ Solar PV panel power $(\mathrm{W})$

$V d c=$ The system voltage in direct current $(\mathrm{V})$

$F_{\text {safe }}=$ The Safe Factor

\section{Costing the PV System}

We prepared the System Requirements Specification (SRS) based on the battery (Voltage/Amp hour), solar $\mathrm{PV}$ panel (Voltage/Wattage) and charge controller (Voltage/Amperage) determined in Equation 3 to $5 \mathrm{We}$ then used the SRS to obtained quotations from various solar system suppliers.

\section{Step II- Trap Housing Fabrication}

We used $40 \times 50 \mathrm{~mm}$ and $40 \times 50 \mathrm{~mm}$ square tubes to fabricate the solar housing, $3 \mathrm{~mm}$ metal sheet to house the battery, $1.2 \times 22 \mathrm{~mm}$ outside diameter GI pipe to hold the Anemometer, $2 \mathrm{~mm}$ sheet metal to house the Charge Controller, Raspberry PI 3 Model B+, Arduino Uno Rev 3 and support the FAW Funnel (green lid/yellow 
funnel/transparent bucket) pheromone trap. We then attached everything to the $3 \times 90 \mathrm{~mm}$ inside diameter black pole.

\section{Step III- Integration}

The $12 \mathrm{~V} 100 \mathrm{Watt}$ solar monocrystalline PV panel is used to generate the electricity and it is connected to a $12 \mathrm{~V} 15 \mathrm{~A}$ charge controller. In order to avoid overcharging, over discharge and electrical overload of the $55 \mathrm{Ah}$ battery, we connect it on the battery side of the charge controller. We then power the raspberry pi using one of the USB port on the charge controller. The pi camera is connected to the CSI camera connector and mounted on the top cover (lip) next to the lure holder of the FAW pheromone trap. The Raspberry Pi 4G/LTE shield with Quectel EC25 Mini PCle 4G/LTE module is connected to one of the USB ports on raspberry pi using the 90-degree right angle micro USB cable in order to achieve maximum data rates as opposed to the UART which is limited to a data rate of about $900 \mathrm{Kbit} / \mathrm{s}$ downlink and uplink. The Arduino Uno is connected to the raspberry pi USB port in a slave mode. The Davis anemometer is connected to pin A4 for wind direction, digital pin 2 for wind speed, $5 \mathrm{~V}$ power and ground on the Arduino Uno while the IR break beam motion sensor is connected to pin 6 on Arduino Uno. The DHT11 Temperature/Humidity sensor is connected to the Arduino Uno 5v pin, GND pin and pin 4. The $3 \mathrm{~W}$ led is connected to 13 and 5 Vpin while the photocell is connected to $5 \mathrm{v}$ pin, GND pin and A0.

The raspberry pi is loaded with Raspbian GNU/Linux 9.9 stretch, python 2.7.13, SQLite database and Arduino IDE 2:1.0.5 dfsg2-4.1. We use python to develop two custom-made programs. The first program captures an image of the funnel path every second alongside environmental conditions and saves the image on the local folder of $16 \mathrm{~Gb} \mathrm{SD}$ card while the temperature, humidity, GPS coordinates, image identifier, wind speed and direction are saved in the SQLite database. The second program sends a picture together with environment conditions to the cloud server together as a JSON object by establish an internet connection using Raspberry Pi 4G/LTE shield with Quectel EC25 Mini PCle 4G/LTE module and Application Programming Interface (API).

\section{Results}

\section{Step I- PV Systems Design}

The automated FAW Pheromone Trap was designed to run for $24 \mathrm{~h}$ per day taking into account the five minimum sunshine hours for Lusaka. When we applied Equation 1, we got a total of 19 battery operated hours. The main components of the automated FAW pheromone trap that required to be powered by Off-grid solar PV system are listed in Table 8. When Equation 2 was applied, we got a total of $412.72 \mathrm{Wh}$ as the system load. Table 8 shows the total system load (power) for each individual system component.

We then applied Equation 3 to determine the battery size in terms of Amp hours. We used a 1.25 safe factor and $12 \mathrm{Vdc}$ due to the max power requirement for Arduino Uno to obtained a 42.99 Ah battery size which was then rounded off to $55 \mathrm{Ah}$ industry offering. We then chose to use a $12 \mathrm{~V} 55$ Ah system voltage lead acid battery because it was readily available on the Zambian market as opposed to a Lithium ion battery of the same size. The detailed specifications for the battery are shown in Table 9. We obtained the solar PV panel wattage by applying Equation 4 . We applied a safe factor of 1.25 and the result was $103.18 \mathrm{~W}$. We then rounded off the wattage and settled for an 100watt monocrystalline panel due to its efficiency and availability on the Zambian market. The detailed specifications of the solar panel are shown in Table 10. Thereafter, we used the solar panel wattage $(100 \mathrm{~W})$ as the PVW, battery voltage $(12 \mathrm{~V})$ as the Vdc and a safe factor of 1.25 to determine the charge controller and the result was an $8.33 \mathrm{~A}$ which we rounded off to $15 \mathrm{~A}$ charge controller due availability. The detailed specifications for the charge controller are shown in Table 11. The total cost of the Off-grid solar PV system came to USS\$ 190.00 as shown in Table 12.

\section{Step II- Trap Housing Fabrication}

Our fabricated trap housing is shown in Fig. 10 and 11 shows the inside of the case housing the Charge Controller, Raspberry PI 3 Model B+ and Arduino Uno Rev 3. The housing case is also used as the holder for the FAW Funnel (green lid/yellow funnel/transparent bucket) pheromone trap.

Table 8: Main component of the automated FAW pheromone trap

\begin{tabular}{llll}
\hline $\begin{array}{l}\text { Item } \\
\text { description }\end{array}$ & $\begin{array}{l}\text { Power Per } \\
\text { item }(\mathrm{W})\end{array}$ & $\begin{array}{l}\text { Hours } \\
\text { per day }\end{array}$ & $\begin{array}{l}\text { Power } \\
\text { per day }\end{array}$ \\
\hline Raspberry PI & 12.500000 & 19 & 237.50 \\
Arduino Uno & 3.000000 & 19 & 57.00 \\
IR Break Beam & 0.150000 & 19 & 2.85 \\
DHT11 & 0.125000 & 19 & 2.38 \\
3G Modem & 3.750000 & 19 & 71.25 \\
PI Camera & 0.150000 & 19 & 2.85 \\
LED & 3.000000 & 12 & 36.00 \\
LDR & 0.002500 & 19 & 0.05 \\
Anemometer & 0.150000 & 19 & 2.85 \\
Total Load & & & 412.72 \\
\hline
\end{tabular}

Table 9: Solar Rechargeable Battery specifications

\begin{tabular}{ll}
\hline Type & AGM sealed lead acid maintenance free \\
\hline Voltage & DC $12 \mathrm{~V}$ \\
Amp Hour & 55 \\
\hline
\end{tabular}


Table 10: Solar PV panel specification

\begin{tabular}{ll}
\hline Type & Monocrystalline \\
\hline Voltage & 12 \\
Wattage & 100 \\
Size Rated Max Voltage & $18.5 \mathrm{~V}$ \\
Rated Max Current & $5.40 \mathrm{~A}$ \\
Open circuit voltage Voc & $21.5 \mathrm{~V}$ \\
Short circuit current Isc & $6.20 \mathrm{~A}$ \\
Dimension & $1 / 4 "$ \\
\hline
\end{tabular}

Table 11: PWM 15A 12/24V Digital Charge Controller specifications

\begin{tabular}{ll}
\hline Charging Mode & PWM (Pulse Width Modulation) \\
\hline Voltage & $12 / 24 \mathrm{~V}$ \\
Current & $15 \mathrm{~A}$ \\
Display Type & Digital \\
Low Voltage Disconnect & $10.8 / 21.6 \mathrm{~V}$ \\
Low Voltage Reconnect & $12.6 / 25.2 \mathrm{~V}$ \\
Built-In Protections & $\begin{array}{l}\text { Over charging, over discharging, } \\
\text { overload and Reverse connection } \\
\text { Automatic identification of system }\end{array}$ \\
Other features & voltage level \\
\hline
\end{tabular}

Table 12: Off-grid solar PV system

\begin{tabular}{lll}
\hline Item description & Quantity & Total price US\$ \\
\hline 100 W Solar PV panel & 1 & 60 \\
15A charger controller & 1 & 15 \\
55Ah battery & 1 & 100 \\
Accessories & 1 & 15 \\
Total & & 190 \\
\hline
\end{tabular}

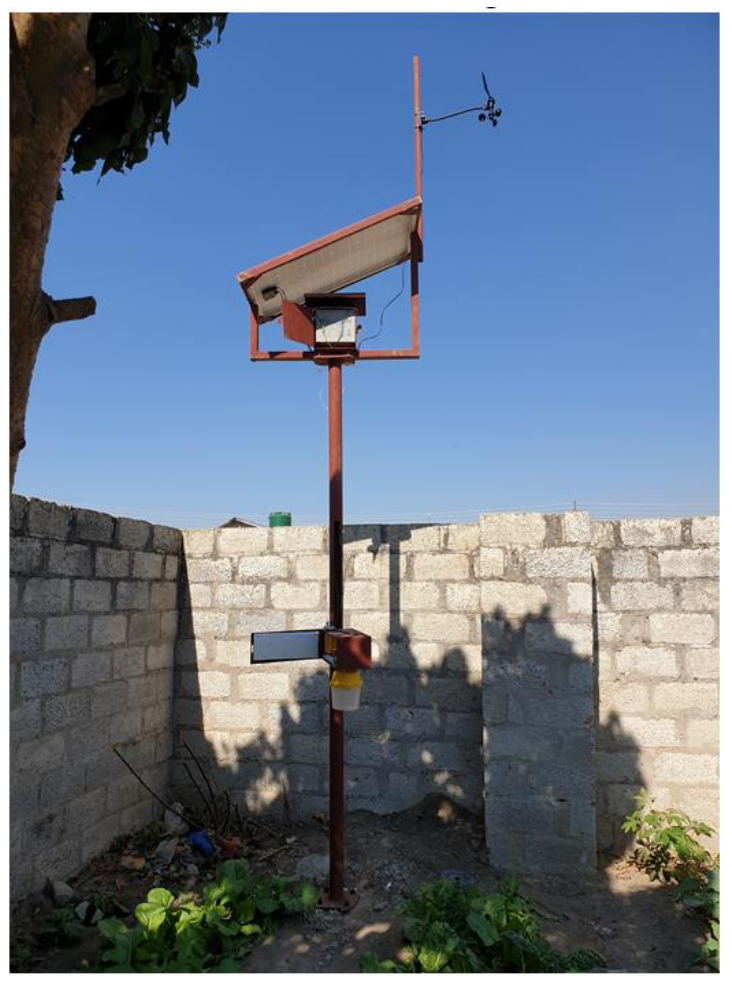

Fig. 10: Fabricated trap housing

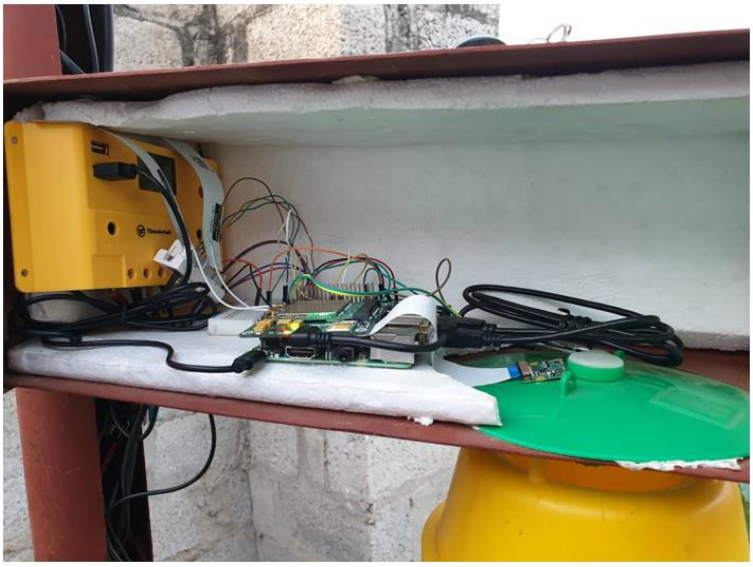

Fig. 11: Housing case for the Charge Controller, Raspberry PI 3 Model B+ and Arduino Uno Rev 3

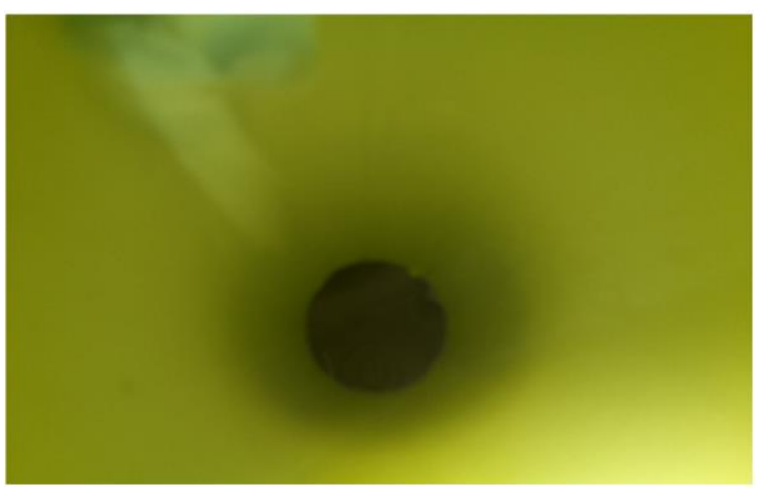

Fig. 12: Moth in flight in the funnel path

\section{Step III- Integration}

Figure 12 shows an image of a moth in flight in the funnel path while Fig.13 shows the local folder with captured images on the Raspberry Pi. Figure 14 shows records corresponding to the captured images alongside temperature, humidity, GPS coordinates, wind speed and direction saved in SQLite database table on the Raspberry Pi. The image identifiers is the primary key and corresponds to the filenames shown in Fig. 13. The image and environmental conditions are combined in a JSON object and uploaded to the cloud server using an API. Figure 15 shows the daily trap capture summaries on the Web Application Dashboard while Fig. 15 shows the details of a single record on a webpage uploaded to the cloud server. The ML attribute (prediction accuracy) is based on the Googles pre-trained InceptionV3 Machine Learning model adopted by Chiwamba et al. (2019) and Chulu et al. (2019b). The model achieved a 90\% plus prediction accuracy for all images that contained a FAW moth as shown in Fig. 16 while a percentage less than $60 \%$ was observed for images that did not contain a FAW moth as shown in Fig. 17. 


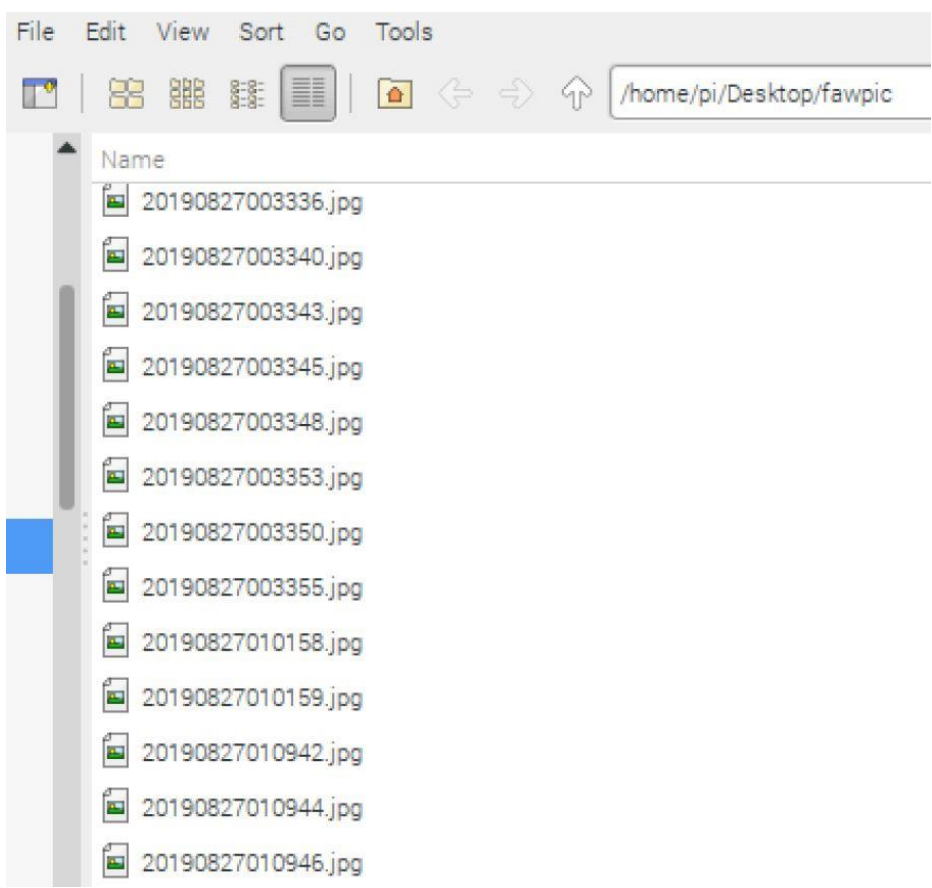

Fig. 13: Local folder with captured images on the Raspberry Pi

\section{pi@raspberrypi: /Desktop/fawpic}

File Edit Tabs Help

sqlite> Select * From Captures;

$1|20190827003336| 19.0|70.0| 14.24343|-15.2656| 1.45 \mid 282 \mathrm{~W}$

$1|20190827003340| 19.2|70,0| 14.24343|-15.2656| 1,45 \mid 282 W$

$1|20190827003343| 19.1|69,0| 14.24343|-15.2656| 0,0 \mid 282 \mathrm{~W}$

$1|20190827003345| 18,9|70,0| 14.24343|-15.2656| 0,0 \mid 282 \mathrm{~W}$

$1|20190827003348| 18.9|70,0| 14.24343|-15.2656| 0,0 \mid 282 \mathrm{~W}$

$1|20190827003350| 18.9|70.0| 14.24343|-15.2656| 0.0 \mid 282 \mathrm{~W}$

$1|20190827003353| 19.0|70,0| 14.24343|-15.2656| \theta, 0 \mid 282 \mathrm{~W}$

$1|20190827003355| 19.0|70.0| 14.24343|-15.2656| 0.0 \mid 282 \mathrm{~W}$

$1|20190827010158| 18.5|72,0| 14.24343|-15.2656| 0,0 \mid 283 \mathrm{~W}$

$1|20190827010159| 18.5|72.0| 14.24343|-15.2656| 0.0 \mid 283 \mathrm{~W}$

Fig. 14: Capture records in SQLite database table on the Raspberry Pi

\begin{tabular}{|l|l|l|l|l|l|l|}
\hline \multicolumn{1}{|c|}{ Top 10 Daily trap captures } & & & & \\
\hline District & Farm & Trap & Avg ${ }^{\circ} \mathrm{C}$ & Avg Hum & Avg Windspeed & Total \\
\hline Chadiza & Simon and Sons & Simon test trap & $19.4^{\circ} \mathrm{C}$ & $66.4 \%$ & $0.3 \mathrm{~km} / \mathrm{h}$ & 10 \\
\hline Showing 1 to 1 of 1 rows & & & & & \\
\hline
\end{tabular}

Fig. 15: Daily trap Capture summaries on the Web Application Dashboard 


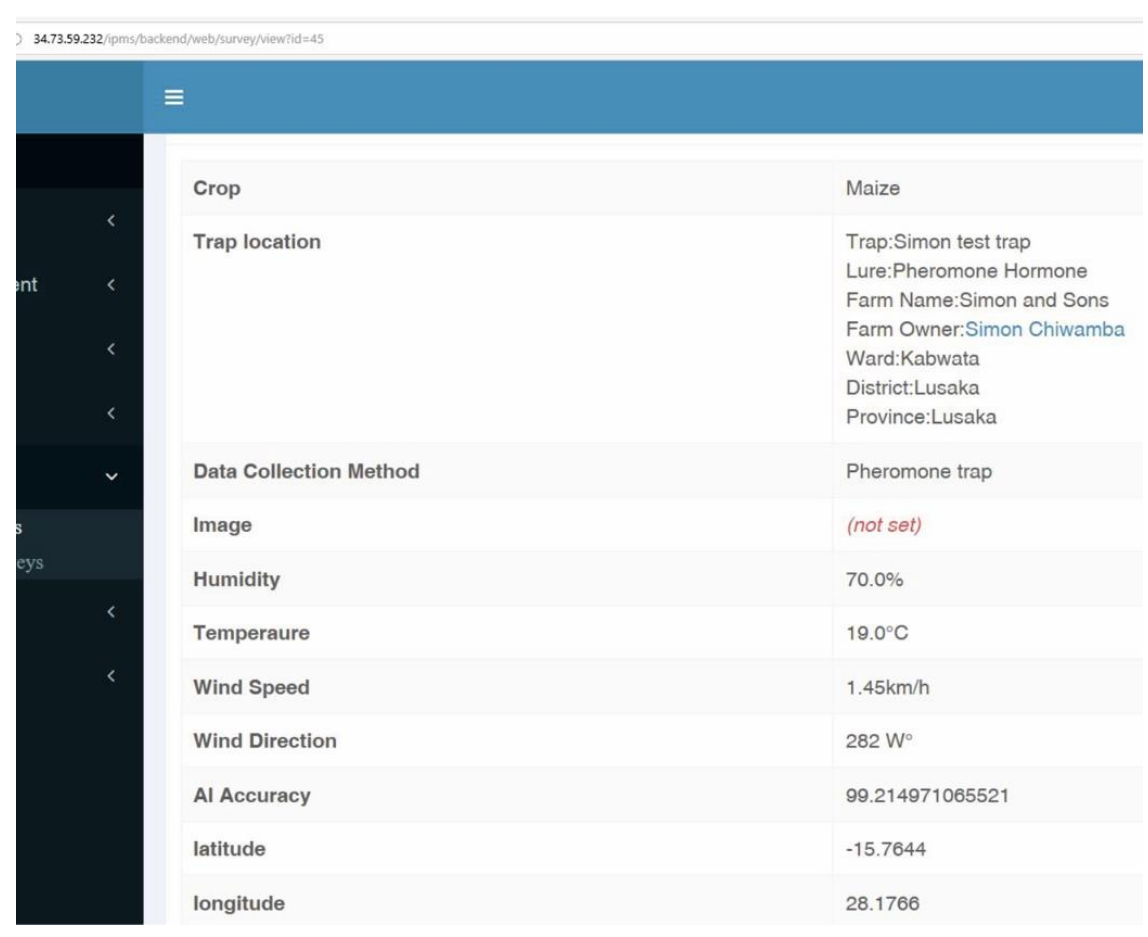

Fig. 16: Detailed single trap capture on the web application

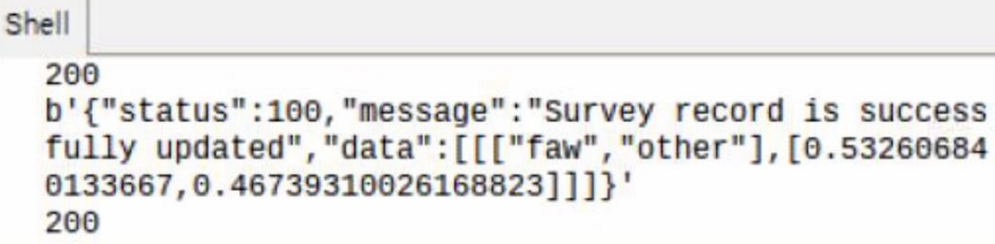

Fig. 17: Prediction Accuracy an image without FAW moth

\section{Discussion}

We modified the FAW trap and integrated it with various sensors which included the camera, temperature, humidity, motion, photocell powered by an off-grid solar PV system for capturing FAW images and environmental conditions in the field. The greatest challenges included but not limited to, off-grid solar PV system configuration, FAW motion sensing and Raspberry PI camera capture timing. We had to upsize or down size the off-grid solar PV system components in order to align them to what was readily available on the Zambian market. On the FAW motion sensing, the IR Break Beam could not detect the FAW moth motion accurately leaving as with the Raspberry PI camera as the only way to remotely monitor the presence of the FAW moth on the trap. After setting the PI camera to capture FAW moth images every second, we observed that the PI camera captures ranged between $1 \mathrm{~s}$ to $5 \mathrm{~s}$ when we cross-checked the image id (record) in the database and image names in the folder. We then adjusted the timing to $5 \mathrm{~s}$ and we instantly observed a $5 \mathrm{~s}$ consistency in the capture interval. Furthermore, we observed that API took more than $5 \mathrm{~s}$ to return prediction accuracy hence adjusting the image data upload to $10 \mathrm{~s}$.

Our modified trap can be improved in a number of areas including but not limited to reduced solar panel and battery size; reduced trap size and weight; integration of optoelectronic sensors similar to the ones used in the work of Potamitis et al. (2015); reduce on the data transfer rate and avoid stressing the cloud server by performing primary image classification on the Raspberry Pi.

\section{Conclusion}

Our automated FAW trap embraces the IoT concepts by integrating a Raspberry Pi 3 Model B+ microcomputer, Atmel 8-bit AVR microcontroller, 3G cellular modem and various sensors powered with an off-grid solar photovoltaic system to capture real time FAW 
moth images and environmental conditions including GPS coordinates, temperature, humidity, wind speed and direction in the field. The captured images together with environmental conditions are uploaded to the cloud server where the images are classified instantly using machine learning to determine whether the image contains a FAW moth or any other insect. The users are provided with an easy to use web application platform that shows near real-time indication of the FAW pest occurrence. Furthermore, users can view the population dynamics of the FAW together with environmental conditions and use the information to design suitable pest control strategies. The designed system has the potential to increase accuracy of monitoring, shorten data collection intervals, reduce field visits and minimize human intervention for a more efficient and effortless early warning and monitoring system that provides a near realtime insight into the FAW situation in the field.

\section{Acknowledgement}

Special thanks goes to the UNZA Department of Computer Science, Department of Biological Sciences, Department of Plant Science and Technology Development and Advisory Unit (TDAU) for the advice and expertise rendered to this project. This work was partly funded by the Food and Agriculture Organization (FAO) of the United Nations (TCP/ZAM/3603).

\section{Funding Information}

We would like to thank the Food and Agriculture Organisation of the United Nations ("FAO") for funding the purchase of materials and tools used in this research project.

\section{Author's Contributions}

Simon H. Chiwamba: Conception and design, acquisition of data and analysis and interpretation of data. Drafting the article and reviewing the article.

Jackson Phiri: Drafting the article and reviewing the article critically for significant intellectual content. Approval of the revised version for to be submitted.

Philip O.Y. Nkunika: Reviewing the article critically for significant intellectual content and giving final approval of the version.

Claytone Sikasote: Conception and design.

Monde M. Kabemba: Reviewing the article critically for significant intellectual content.

Miyanda N. Moonga: Acquisition of data and reviewing the article critically for significant intellectual content.

\section{Ethics}

We, the authors agree with the publication of this manuscript and confirm that it does not contain ethical issues. All cited references are stated in the references section.

\section{References}

Abdelkader, R.M., A. Al-Salaymeh, Z. Al-Hamamre and F. Sharaf, 2010. A comparative analysis of the performance of monocrystalline and multicrystalline PV cells in semi-arid climate conditions: The case of Jordan. Jordan J. Mech. Industrial Eng., 4: 543-552.

Adfruit, 2019. IR break beam sensor-3mm LEDs.

Ahmad, N.S. and N. Kamarudin, 2011. Pheromone trapping in controlling key insect pests: Progress and prospects. Oil Palm Bull., 62: 12-24.

AlShemmary, A.N.E., L.M. Kadhom and W.J. AlFahham, 2019. Information technology and standalone solar Systems in tertiary institutions. Energy Proc., 36: 369-379.

DOI: 10.1016/j.egypro.2013.07.042

Anderson, M.K., Y. Hillbur, J. Reber, B. Hanson and O.R. Ashley et al., 2012. Using sex pheromone trapping to explore threats to wheat from hessian fly (Diptera: Cecidomyiidae) in the upper great plains. J. Econ. Entomol., 105: 1988-1997.

DOI: $10.1603 / \mathrm{EC} 12011$

Ayaz, M., A. Uddin, Z. Sharif, A. Mansour and E. Aggoune, 2019. Internet-of-Things (IoT) based Smart Agriculture: Towards making the fields talk. IEEE Access.

Baker, H.G., C.R. Tann and G.P. Fitt, 2011. A tale of two trapping methods: Helicoverpa spp. (Lepidoptera, Noctuidae) in pheromone and light traps in Australian cotton productions systems. Bull. Entomol. Res., 101: 9-23. DOI: $10.1017 / \mathrm{S} 0007485310000106$

Banson, E.K., D.K. Asare, F.D. Dery, K. Boakye and A. Boniface et al., 2019. Impact of Fall Armyworm on Farmer's Maize: Systemic Approach. 1st Edn., Springer, ISSN-10: 1573-9295, pp: 128.

Bayrak, G. and M. Cebec, 2011. A PV based automation system for fish farms: An application study. Proceedings of the 7 th International Conference on Electrical and Electronics Engineering, Dec. 1-4, IEEE Xplore Press, Bursa, Turkey.

Bilal, M., 2017. A review of internet of things architecture, technologies and analysis Smartphonebased attacks against 3D printers.

Cactus, 2014. How to hookup Davis anemometer to Arduino (Part 1 of 3).

Calderon, R.A., 2017. Solar powered rice black bug light trap. Proceedings of the 6th International Conference on Advances in Science, Engineering and Technology, Dec. 17-18, Philippines.

Camacho, E.F., M. Berengue, I. Alvarado and D. Limon, 2010. Control of solar power systems: A survey. IFAC Proc. Volumes, 43: 817-822. DOI: $10.3182 / 20100705-3-B E-2011.00135$ 
Capinera, J.L., 2007. Fall armyworm, Spodoptera frugiperda (J.E. Smith) (Insecta: Lepidoptera: Noctuidae). Department of Entomology and Nematology.

Cereals, 2019. Fall army worms: Enjoy amiran's knowledge, succeed in control. Scoop Communications, Nairobi, Kenya.

Chihana, S., J. Phiri and D. Kunda, 2018. An IoT based warehouse intrusion detection (E-Perimeter) and grain tracking model for food reserve agency. Int. J. Adv. Comput. Sci. Applic., 9: 213-222. DOI:10.14569/IJACSA.2018.090929

Chiwamba, H.S., J. Phiri, P.O.Y. Nkunika, M. Nyirenda and M.M. Kabemba et al., 2019. Machine learning algorithms for automated image capture and identification of Fall Armyworm (FAW) moths. Zambia Inform. Commun. Technol. J., 3: 1-4.

DOI: 10.33260/zictjournal.v3i1.69

Chiwamba, H.S., J. Phiri, P.O.Y. Nkunika, M. Nyirenda and M.M. Kabemba et al., 2018. An application of machine learning algorithms in automated identification and capturing of Fall Armyworm (FAW) moths in the field. Proceedings of the ICTSZ International Conference in ICT's, Dec. 12-13, Lusaka, Zambia.

DOI: 10.33260/zictjournal.v3i1.69

Chulu, F., J. Phiri, M. Nyirenda, M.M. Kabemba and P.O.Y. Nkunika et al., 2019b. Developing an automatic identification and early warning and monitoring web based system of fall army worm based on machine learning in developing countries. Zambia Inform. Commun. Technol. J., 3: 13-20. DOI: 10.33260/zictjournal.v3i1.71

Chulu, F., J. Phiri, P. Nkunika, M. Nyirenda and M.M. Kabemba et al., 2019a. A convolutional neural network for automatic identification and classification of fall army worm moth. Int. J. Adv. Comput. Sci. Applic.

Climatemps, 2019. Sunshine and daylight hours in Lusaka, Zambia.

Cluz, I., M.C.L. Figueiredo, R.B. Silva, I.F. Silva and C.S. Puala et al., 2012. Using sex pheromone traps in the decision-making process for pesticide application against fall armyworm (Spodoptera frugiperda [smith][lepidoptera: noctuidae]) larvae in maize. IJPM, 58: 83-90.

DOI: 10.1080/09670874.2012.655702

Cock, M.J.W., K.P. Beseh, A.G. Buddie, G. Cafá and J. Crozier, 2017. Molecular methods to detect Spodoptera frugiperda in Ghana and implications for monitoring the spread of invasive species in developing countries. Scientific Repor.

Crabtree, W.G. and N.S. Lewis, 2007. Solar energy conversion. Phys. Today, 60: 37-42.

DOI: $10.1063 / 1.2718755$
Cvijikj, P.I. and F. Michahelles, 2011. The Toolkit Approach for End-user Participation in the Internet of Things. In: Architecting the Internet of Things, Uckelmann, D., M. Harrison and F. Michahelles (Eds.), Springer, Berlin, pp: 65-97.

Daniel, C., D. Mohanty, J. Li and D.L. Wood, 2014. Cathode materials review. AIP Conf. Proc., 1597: 26-43. DOI: $10.1063 / 1.4878478$

DAVIS, 2019. Anemometer for weather monitor or wizard.

Day, R., P. Abrahams, M. Bateman, T. Beale and V. Clottey et al., 2017. Witt fall armyworm: Impacts and implications for Africa. Outlooks Pest Manage., 28: 196-201. DOI: 10.1564/v28_oct_02

Ding, W. and G.W. Taylor, 2016. Automatic moth detection from trap images for pest management. Comput. Electron. Agric., 123: 17-28.

Eliopoulos, P., N. Tatlas, I. Rigakis and I. Potamitis, 2018. A smart trap device for detection of crawling insects and other arthropods in urban environments. Electronics.

Facello, A. and E. Cavallo, 2013. Insects remote detection in pheromones traps. Proceedings of the EFITA-WCCA-CIGR Conference, Jun. 24-27, Italy.

FAO, 2018. FAW guidance note 3: Fall armyworm trapping.

Ferdoush, S. and X. Li, 2014. Wireless sensor network system design using raspberry $\mathrm{Pi}$ and Arduino for environmental monitoring applications. Proc. Comput. Sci., 34: 103-110.

DOI: $10.1016 /$ j.procs.2014.07.059

Gour, R., 2018. Top 10 applications of IoT. DZone.

Guerrero, S., J. Brambila and R.L. Meagher, 2014. Efficacies of four pheromone-baited traps in capturing male helicoverpa (Lepidoptera: Noctuidae) moths in northern Florida. Bio. One, 97: 1671-1678. DOI: 10.1653/024.097.0441

Haikun, T.L.X., L. Haitao and Y. Xiao-Guang, 2018. Research and application of the IOT gateway based on the real-time specification for Java. Int. J. Online Biomed. Eng., 14: 129-141.

DOI: $10.3991 /$ ijoe.v14i03.8419

Holguin, G.A., L.B. Lehman, A.L. Hull, P.V. Jones and J. Park, 2010. Electronic traps for automated monitoring of insect populations. IFAC Proc.

Husain, A., W.Z.W. Hasan, S. Shafie, M.N. Hamidon and S. S. Pandey, 2018. A review of transparent solar photovoltaic technologies. Renewable Sustainable Energy Rev., 94: 779-791.

DOI: 10.1016/j.rser.2018.06.031

IAPRI, 2018. Fall armyworm outbreak in Zambia: Responses, impact on maize production and food security. Indaba Agricultural Policy Research Institute (IAPRI), Lusaka, Zambia. 
IAPRI, 2019. Fall armyworm outbreak in Zambia: Responses, impact on maize production and food security. Indaba Agricultural Policy Research Institute (IAPRI).

Indiamart, 2019. Pheromone delta phero sensor trap for agriculture.

Kong, L.B.A.M., 2017. Universidad de Zamboanga weather station: Monitoring on wind speed and wind direction. Int. J. Applied Eng. Res., 12: 14914-14926.

Kumela, T., J. Simiyu, B. Sisay, P. Likhayo and E. Mendesil et al., 2018. Farmers' knowledge, perceptions and management practices of the new invasive pest, fall armyworm (Spodoptera frugiperda) in Ethiopia and Kenya. Int. J. Pest Manage., 0874: 1-9.

DOI: $10.1080 / 09670874.2017 .1423129$

Kwasek, M., 2012. Threats to food security and common agricultural policy. Econ. Agric., 59: 701-713.

LSU,

2019.

https://www.lsuagcenter.com/ /media/system/0/5/0/8/0 50869493d5a066be3d4c7a5741f7c08/photo_4.jpg

Maksimović, M., V. Vujović, N. Davidović, V. Milošević and B. Perišić, 2016. Raspberry Pi as internet of things hardware: Performances and constraints. Proceedings of the 3rd International Conference on Electrical, Electronic and Computing Engineering, Jun. 13-16, Serbia.

Marcelino, P., 2018. Transfer learning from pre-trained models: How to solve any image classification problem quickly and easily.

Marković, D., S. Siniša Ranđić, S. Tanasković and S. Gvozdenac, 2017. Possibility of monitoring D.v. virgifera flight by processing image of phero-traps using Raspberry Pi based devices. Acta Agric. Serbica, 44: 207-217. DOI: $10.5937 / A A S e r 1744207 \mathrm{M}$

Martineau, M., D. Conte, R. Raveaux, I. Arnault and D. Munier et al., 2017. Survey on image-based insect classification. Patt. Recog., 65: 273-284.

DOI: 10.1016/j.patcog.2016.12.020

Maya, J.G., A. Davidson and B. Monahov, 2018. Lead batteries for utility energy storage: A review. J. Energy Storage, 15: 145-157.

DOI: 10.1016/j.est.2017.11.008

Meagher, L.R., 2001. Trapping fall armyworm (Lepidoptera: Noctuidae) adults in traps baited with pheromone and a synthetic floral volatile compound. Florida Entomol., 84: 288-292.

DOI: $10.2307 / 3496181$

Mitchell, R.E., 1979. Monitoring adult population of the fall armyworm. Fall Armyworm Symposium, 62: 91-98. DOI: $10.2307 / 3494085$

MoA, 2019a. Crop forecasting survey for the 2018/2019 agricultural season. Ministry of Agriculture.
MoA, 2019b. Training in fight against fall armyworm. Ministry of Agriculture.

MoNDP, 2018. Strategic Plan for Agriculture and Rural Statistics (SPARS) Zambia 2019-2023. Ministry of National Development Planning, Central Statistical Office, Lusaka, Zambia.

Muangprathub, J., N. Boonnam, S. Kajornkasirat, N. Lekbangpong and A. Wanichsombat et al., 2019. IoT and agriculture data analysis for smart farm. Comput. Electron. Agric., 156: 467-474.

DOI: 10.1016/j.compag.2018.12.011

Muminov, A., Y.C. Jeon, D. Na, C. Lee and S.H. Jeon, 2017. Development of a solar powered bird repeller system with effective bird scarer sounds. Proceedings of the International Conference on Information Science and Communications Technologies, Nov. 2-4, IEEE Xplore Press, Tashkent, Uzbekistan.

DOI: 10.1109/ICISCT.2017.8188587

Mwanza, M., J. Chachak, N.S. Çetin and K. Ülgen, 2017. Assessment of solar energy source distribution and potential in Zambia. Periodicals Eng. Natural Sci., 5: 103-116.

DOI: $10.21533 /$ pen.v5i2.71

Nagoshi, R.N., S. Fleischer and L.R. Meagher, 2009. Texas is the overwintering source of fall armyworm in Central Pennsylvania: Implications for migration into the north-eastern United States. Environ. Entomol., 38: 1546-1554.

DOI: $10.1603 / 022.038 .0605$

Negnevitsky, M., 2005. Artificial Intelligence: A Guide to Intelligent Systems. 2nd Edn., Pearson, Harlow, England, ISBN-10: 0321204662, pp: 415.

Otim, M.H., W.T. Tay, T.K. Walsh, D. Kanyesigye and S. Adumo et al., 2018. Detection of sister-species in invasive populations of the fall armyworm Spodoptera frugiperda (Lepidoptera: Noctuidae) from Uganda. PloS One, 13: e0194571-e0194571. DOI: 10.1371/journal.pone.0194571

Patel, M., 2019. What is machine learning? Types of machine learning. Medium Corporation, California, United States.

Plessis, H., J. Berg, N. Ota and D.J. Kriticos, 2018. Spodoptera frugiperda (Fall Armyworm). CSIROInSTePP Pest Geography.

Potamitis, I., I. Rigakis and K. Fysarakis, 2014. The electronic McPhail trap. Sensors, 14: 22285-22299. DOI: $10.3390 / \mathrm{s} 141222285$

Potamitis, I., I. Rigakis and K. Fysarakis, 2015. Insect biometrics: Optoacoustic signal processing and its applications to remote monitoring of McPhail type traps. PLoS One, 10: e0140474-e0140474.

DOI: 10.1371/journal.pone.0140474 
Prasanna, B., J. Huesing, R. Eddy and V. Peschke, 2018. Fall armyworm in Africa: A guide for integrated pest management.

Raspberry, 2019. Camera module V2.

Sethi, P. and S.R. Sarangi, 2017. Internet of things: Architectures, protocols and applications. J. Electr. Comput. Eng. DOI: 10.1155/2017/9324035

Shi, X., X. An, Q. Zhao, H. Liu and L. Xia et al., 2019. State-of-the-art internet of things in protected agriculture. Sensors, 19: 1833-1833.

DOI: $10.3390 / \mathrm{s} 19081833$

Sixfab, 2019a. Quectel EC25 mini PCle 4G/LTE Module

Sixfab, 2019b. Raspberry Pi 3G-4G/LTE Base Shield V2.

Smale, M., D. Byerlee and T.S. Jayne, 2011. Maize revolutions in sub-Saharan Africa.

Taşçıŏlu, A., O. Taşkın and A. Vardar, 2016. A power case study for monocrystalline and polycrystalline solar panels in bursa city turkey. Int. J. Photoenergy. DOI: $10.1155 / 2016 / 7324138$
Thompson, S., 2016. Four threats to global food security and what we can do about them. The Conversation, Braamfontein, South Africa.

Vermesan, O., P. Friess, P. Guillemin, H. Sundmaeker and M. Eisenhauer et al., 2013. Internet of things strategic research and innovation agenda.

Yassein, B.M., M. Shatnawi and D. Al-Zoubi, 2016. Application layer protocols for the internet of things. Proceedings of the IEEE International Conference on Internet of Things and Pervasive Systems, Sep. 22-24, IEEE Xplore Press, Agadir, Morocco. DOI: 10.1109/ICEMIS.2016.7745303

Yelizavet, D.P.D. and O.M. Florentino, 2019. Internet of Things platform (IoT)-comparison of layered architectures. Int. J. Eng. Trends Technol., 67: 4-10. DOI: 10.14445/22312803/IJCTT-V67I1P102

Zhong, Y., J. Gao, Q. Lei and Y. Zhou, 2018. A visionbased counting and recognition system for flying insects in intelligent agriculture. Sensors. 